\title{
Developing New Antimicrobial Therapies: Are Synergistic Combinations of Plant Extracts/Compounds with Conventional Antibiotics the Solution?
}

\author{
Matthew J. Cheesman ${ }^{1,2}$, Aishwarya Ilanko ${ }^{3}$, Baxter Blonk ${ }^{3}$, lan E. Cock ${ }^{3,4}$ \\ 'School of Pharmacy and Pharmacology, Gold Coast Campus, Griffith University, Parklands Drive, Southport, ${ }^{2}$ Menzies Health Institute Queensland, Quality Use of \\ Medicines Network, Queensland 4222, ${ }^{3}$ School of Natural Sciences, Nathan Campus, Griffith University, ${ }^{4}$ Environmental Futures Research Institute, Nathan Campus, \\ Griffith University, Nathan, Queensland 4111, Australia
}

\begin{abstract}
The discovery of penicillin nearly 90 years ago revolutionized the treatment of bacterial disease. Since that time, numerous other antibiotics have been discovered from bacteria and fungi, or developed by chemical synthesis and have become effective chemotherapeutic options. However, the misuse of antibiotics has lessened the efficacy of many commonly used antibiotics. The emergence of resistant strains of bacteria has seriously limited our ability to treat bacterial illness, and new antibiotics are desperately needed. Since the discovery of penicillin, most antibiotic development has focused on the discovery of new antibiotics derived from microbial sources, or on the synthesis of new compounds using existing antibiotic scaffolds to the detriment of other lines of discovery. Both of these methods have been fruitful. However, for a number of reasons discussed in this review, these strategies are unlikely to provide the same wealth of new antibiotics in the future. Indeed, the number of newly developed antibiotics has decreased dramatically in recent years. Instead, a reexamination of traditional medicines has become more common and has already provided several new antibiotics. Traditional medicine plants are likely to provide further new antibiotics in the future. However, the use of plant extracts or pure natural compounds in combination with conventional antibiotics may hold greater promise for rapidly providing affordable treatment options. Indeed, some combinational antibiotic therapies are already clinically available. This study reviews the recent literature on combinational antibiotic therapies to highlight their potential and to guide future research in this field.
\end{abstract}

Key words: $\beta$-lactamase, clavulanic acid, efflux pump inhibitors, multi-drug resistance, superbugs, synergy

\section{INTRODUCTION}

Despite the advancements of modern medicine, bacteria continue to pose one of the greatest risks to human health. Since the discovery of penicillin in 1929 by Fleming, ${ }^{[1]}$ microbial-derived antibiotics have completely revolutionized antibacterial therapy. Indeed, penicillin became the main therapeutic option for infectious diseases. Furthermore, that discovery resulted in a new field of antibacterial drug discovery from bacteria and fungi which has provided medicine with a myriad of new, highly effective antibiotic compounds. However, by the 1940s, widespread use of penicillin resulted in the emergence of new strains of microbes capable of destroying the drug and negating its effects. ${ }^{[2,3]}$ Similarly, bacteria have developed resistance to many other commonly used antibiotics [Figure 1]. ${ }^{[4]}$ This emerging trend is concerning and is considered by the World Health Organization (WHO) to be perhaps the most urgent issue facing medical science. ${ }^{[5]}$

\section{Correspondence:}

Dr. Ian E. Cock

Environmental Futures Research Institute, Nathan Campus,

Griffith University, Nathan, Queensland 4111, Australia.

E-mail: I.Cock@griffith.edu.au

\begin{tabular}{|l|l|}
\hline \multicolumn{3}{|c|}{ Access this article online } \\
\hline Quick Response Code: & Website: \\
\hline & www.phcogrev.com \\
\hline
\end{tabular}

Bacteria are the oldest and most prevalent organisms on earth. They are varied, versatile, and are commensal to all mammals. They can be both crucial and detrimental to health, depending on host interactions. Climate, habitat, ethnicity, genetics, diet, and activity cause the microbiome to fluctuate in diversity and may alter host susceptibility to opportunistic pathogens. Evolutionarily, humans have learned to coexist with various microbes that are omnipresent on this planet. Although certain microbes can be mutualistic, there is a large proportion that are pathogenic and can cause a myriad of potentially life-threatening infectious diseases. Surprisingly, many of the bacteria which cause human disease are also essential to the human microbiome. ${ }^{[6]}$ Consuming drugs alters the balance of microbe populations in the gut and may instigate a range of adverse effects while still providing treatment for specific diseases. Some bacteria may persist over susceptible populations by resisting the drug altogether. Multidrug resistance (MDR), is defined as nonsusceptibility to at least one agent in more than two of the known categories for antimicrobials. ${ }^{[7]}$ Pathogens which are recognized as extensively drug-resistant (XDR) are susceptible to only two or fewer of the antimicrobial categories, and thus, pose a substantial threat to human health.

Concurrent with the increased incidence of bacterial resistance to antibiotics, there has been a corresponding decrease in antimicrobial

This is an open access article distributed under the terms of the Creative Commons Attribution-NonCommercial-ShareAlike 3.0 License, which allows others to remix, tweak, and build upon the work non-commercially, as long as the author is credited and the new creations are licensed under the identical terms.

For reprints contact: reprints@ @edknow.com

Cite this article as: Cheesman MJ, llanko A, Blonk B, Cock IE. Developing new antimicrobial therapies: Are synergistic combinations of plant extracts/compounds with conventional antibiotics the solution? Phcog Rev 2017;11:57-72. 


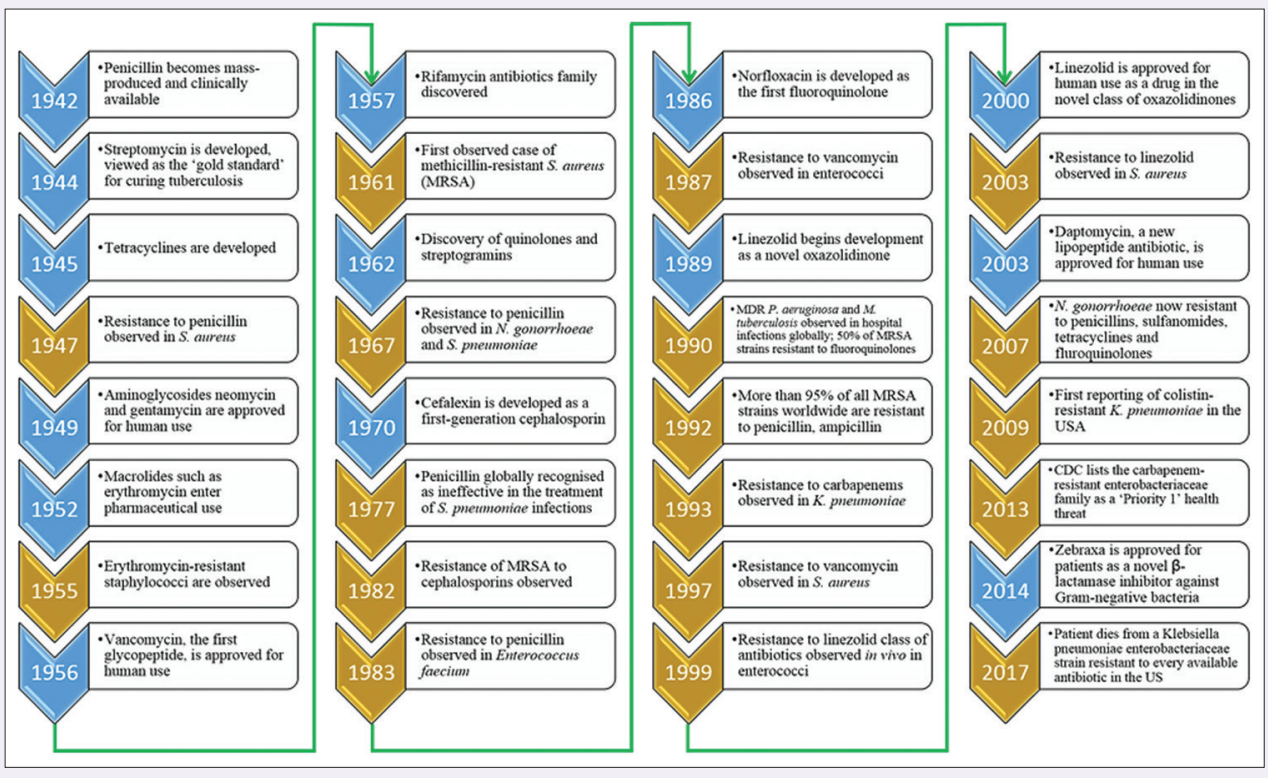

Figure 1: The timeline of antibiotic development and the evolution of resistance. Blue arrows indicate antibiotic discovery and commercialization events, whereas gold arrows represent bacterial resistance to antibiotics observed in patients

discovery. This has directed researchers toward alternative therapies, including traditional plant-based medicines, bacteriophage therapies, and combinational therapies. This review discusses bacterial resistance mechanisms and strategies (both common and novel) in the development of new antibiotic therapies. In so doing, we highlight the use of plant natural products and plant extracts, particularly in synergistic combinations, as having particular promise for rapidly developing new, effective treatment modalities available to combat pathogens resistant to conventional antibiotic therapies.

\section{A BRIEF HISTORY OF ANTIBIOTICS}

Until the early part of the $20^{\text {th }}$ century, the treatment of pathogenicinfections relied on traditional medicines (usually plant material). The discovery of penicillin completely revolutionized the treatment of infectious diseases. This serendipitous discovery resulted from a chance observation that the growth of Staphylococcus aureus was inhibited by a blue mold (a fungus from the Penicillium genus) in culture dishes ${ }^{[1]}$ demonstrating that some microorganisms are capable of producing substances that can inhibit the growth of other microbial species. The discovery of penicillin was the start of a new era of treatment options for bacterial infections ${ }^{[8]}$ From that time, until the latter part of the last century, there was an exponential increase in the number of antibiotics discovered. Within decades of discovering penicillin and the sulfonamides, various other antimicrobial agents of varying properties were introduced to clinicians. ${ }^{[9]}$ Indeed, twenty new classes of antibiotics were developed in the two decades following the introduction of penicillin for clinical use, including $\beta$-lactams, aminoglycosides, tetracyclines, macrolides, fluoroquinolones, and cephalosporins. Modified $\beta$-lactams and $\beta$-lactamase inhibitors provided effective treatment and management of the entire Enterobacteriaceae family. ${ }^{[10]}$ Another novel class of antibiotics would not be introduced again until 1989. Each class of antibiotics has a unique core structure (scaffold). Subsequently, many antibiotics have been developed through synthetic tailoring of these scaffolds. The discoveries during the mid-1930s to the early 1960s determined the chemical scaffolds of the majority of antibiotics used today. Existing antibiotics were subsequently modified to reduce toxicity, improve their spectrum of activity or cross-assayed to test increased efficacy with other antibiotics. ${ }^{[1]}$ Scaffolds of cephalosporins, penicillins, quinolones, and macrolides constitute almost three-quarters of the new antibiotics discovered between 1981 and 2005. ${ }^{[12]}$ The golden age of antibiotic discovery ended in the early 1960s, and the evolution of bacterial resistance has since superseded drug discovery. A timeline of antibiotic implementation and the rise of drug resistance is shown in Figure 1.

The improper and misuse of antibiotics has resulted in the widespread development of resistance by many bacterial species. ${ }^{[13,14]}$ As a consequence, two main events have occurred in parallel throughout the last century. The discovery of antimicrobial agents has steadily decreased to no more than a few antibiotics synthesized or discovered in the last decade. ${ }^{[9]}$ Simultaneously, antibiotic resistance has rapidly increased, creating multi-resistant organisms that are becoming difficult to manage given the current antibiotic treatment regimens. ${ }^{[15]}$ The development of alternative treatment methods is crucial and considered by WHO to be perhaps the biggest challenge facing medical science. ${ }^{[5]}$

\section{Antibiotic function}

Antibiotics function to kill bacteria or inhibit their growth in a number of ways [Figure 2a]. Depending on their class, antibiotics may halt the synthesis of proteins and metabolites, disrupt binary fission, or damage the integrity of the cell wall. ${ }^{[16]}$ Bacteria can develop resistance innately by selective pressures or acquire the resistance machinery from neighboring microbes. Bacteria deploy mobile resistance elements (MREs), including transposons, plasmids, and integrons, carrying the genetic material required to confer resistance but not the genes essential for cell function. MREs can be transmitted between bacteria of different phyla either directly between adjacent cells (conjugation) or indirectly by salvaging intact elements (transformation). Selective pressures for MREs essential for survival promote the preservation of drug resistance mechanisms in bacterial progeny. ${ }^{[11,17]}$

\section{EVOLUTION OF BACTERIAL RESISTANCE}

The "Golden Age" of antibiotics saw the development of hundreds of antimicrobials for curing infectious diseases. This eruption of new drugs approved for human use, together with vaccinations, ended several 


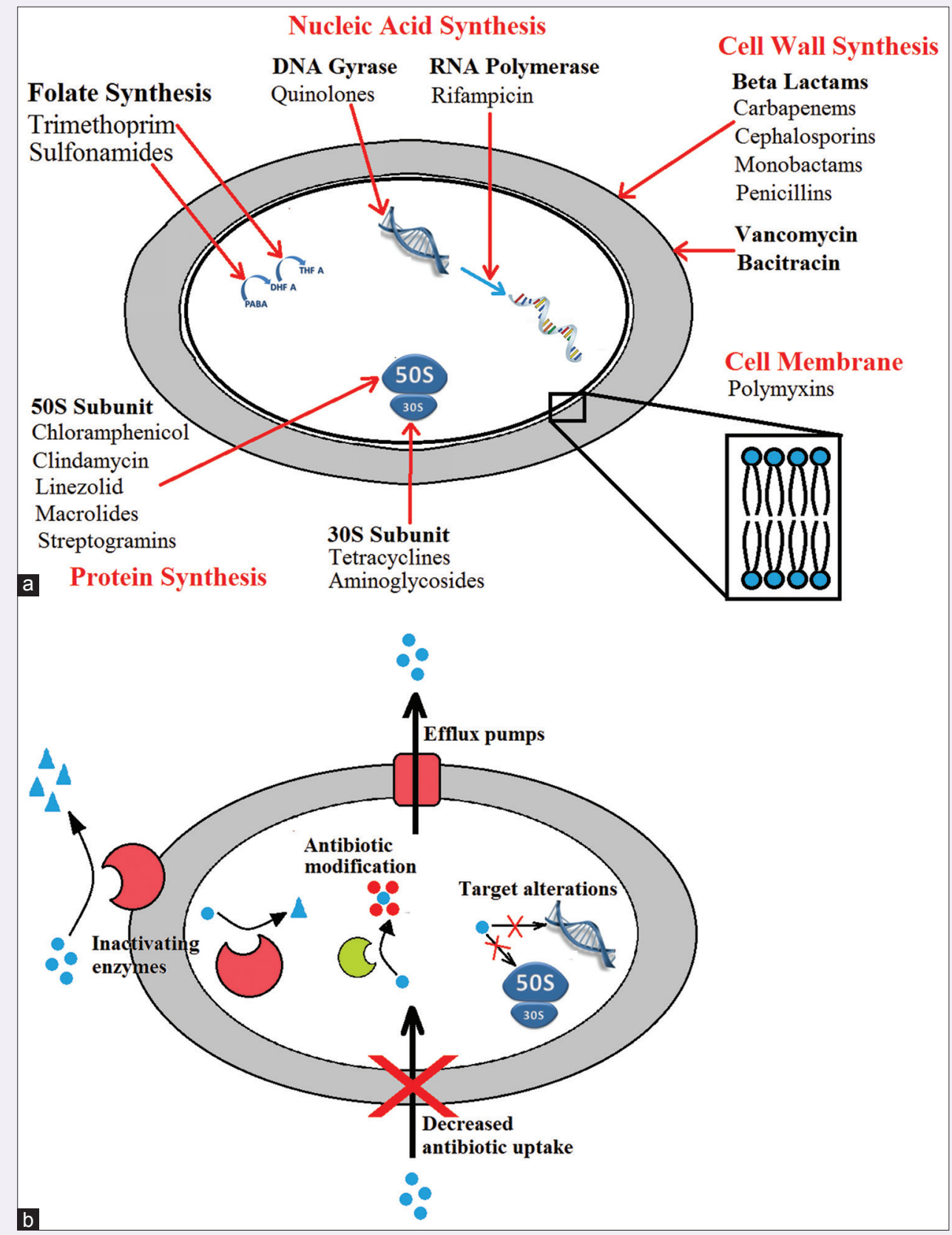

Figure 2: (a) Antibiotic targets and (b) bacterial resistance mechanisms

major trends in infectious diseases. Half of all post-birth deaths caused by Streptococcus pyogenes could be prevented with a 4-day prescription of penicillin. S. aureus infections became far less serious, with mortality rates declining an estimated $80 \%$. Other diseases such as impetigo or leprosy became rare or disappeared entirely in developed countries. ${ }^{[18]}$ However, the effectiveness of many of these early antibacterial agents is now limited due to the development of resistance by many bacterial strains. Several factors contribute to the increase in antibiotic-resistant bacterial strains. The use of antibiotics has increased at an exponential rate throughout many industries. ${ }^{[4]}$ Due to high demands, the production of antibiotics has improved in efficiency and lowered in cost. As a result, these drugs are released into the environment at a significant rate, contributing to the selection of resistant strains. Numerous pathogenic microbes have acquired multiple drug resistance, including Streptococcus pneumoniae, a causative agent of various common diseases such as otitis media, pneumonia, and meningitis. ${ }^{[15]}$ Around two-thirds of all ear infections are bacterial, and approximately, $85 \%$ of the cases can be resolved without the need for antibiotic treatment. However, antibiotics are still prescribed to almost every child in the United States presenting with an ear infection, further contributing to this resistance. As a result of misuse, penicillin can no longer be relied on for the treatment of meningitis caused by $S$. pneumoniae. This, together with the overuse or misuse of antibiotics, has inflicted various selective pressures on pathogenic microbes, promoting resistance.

\section{Multi-resistant strains of microbes: "Superbugs"}

The number of MDR microbes (commonly known as superbugs) is increasing at a significant rate as a result of widespread antibiotic misuse. 
These MDR microbes increase the rate of morbidity and mortality due to multiple mutations in related diseases. ${ }^{[19,20]}$ Thus, the therapeutic options available for these diseases are significantly reduced. Certain strains of MDR microbes have also acquired increased virulence and enhanced transmissibility. Tuberculosis currently affects around a third of the human population. ${ }^{[21]}$ Although streptomycin and isoniazid have previously provided effective treatment for this disease, the development of resistance was rapid, and XDR strains and totally drug resistant (TDR) forms of the pathogen have evolved. ${ }^{[21,22]}$ Similarly, S. aureus became resistant to penicillin treatment relatively soon after its discovery. Methicillin (the first designer anti-resistance antibiotic) was introduced in 1960 in the defense against penicillinases, ${ }^{[23]}$ with the emergence of methicillin-resistant $S$. aureus (MRSA) arising shortly thereafter. ${ }^{[24,25]}$ The establishment of MRSA within the community may be due to the overuse of antibacterial-containing substances in common household and hospital cleaning products to achieve a "super clean" environment. ${ }^{[26]}$ Triclosan is a nonspecific biocide which has been used in clinics and hospitals for many decades. The overuse of triclosan in soaps, disinfectants, and clothes detergents has led to the formation of triclosan-resistant pathogenic strains, including MRSA. ${ }^{[27,28]}$ Likewise, the misuse of various other antimicrobial agents has led to the formation of many MDR pathogens, and this requires urgent attention before antibiotic resistance becomes more difficult to control.

\section{Resistance mechanisms}

Bacteria have developed numerous methods with which to resist antibiotic action [Figure 2b]. The drug insensitivity in antibiotic-resistant bacterial strains is generally due to resistance genes and their downstream effects. The genes are transported through plasmids that favor the survival of the bacteria in various destructive environments. Resistance genes may code for efflux pumps which eject antibiotic from the cells, as well as genes that induce antibiotic-degrading/inactivating enzymes. These traits can be inherited, imported from other pathogens, or may occur through random mutations in bacterial DNA. ${ }^{[29,30]}$ Furthermore, microbes can avoid antibiotic attack through several other mechanisms. A summary of some of the major antibiotic drug classes and bacterial resistance mechanisms is shown in Table 1. Each type or class of antibiotic can be exposed to greater than one single mechanism of resistance and thus may develop MDR, XDR, or TDR.

Bacterial resistance mechanisms may work to inhibit membrane permeability to antibiotics, produce enzymes which neutralize antibiotics or change the antibiotic target to neutralize the interaction. ${ }^{[31]}$ The mechanisms may be specific to a target antibiotic or have a broad spectrum of activity. Often, antibiotics must be modified or used in combination against MDR bacteria to avoid these mechanisms. ${ }^{[32]}$ For example, $\beta$-lactams (e.g., penicillin, ampicillin, and carbenicillin) are often used in combination with $\beta$-lactamase enzyme inhibitors. Modified $\beta$-lactams, (e.g., methicillin, oxacillin), are immune to degradation by narrow-spectrum $\beta$-lactamases. Methicillin-resistant Staphylococcus spp. utilize extended-spectrum $\beta$-lactamases (ESBLs) to resist the modified $\beta$-lactams, ${ }^{[33]}$ or mutate their penicillin binding protein (PBP) to render it unable to bind adequately to penicillin-like drugs. ${ }^{[34]}$

Table 1: Antibiotics in clinical use and modes of resistance

\begin{tabular}{|c|c|c|c|}
\hline Antibiotic class & Examples & Drug target & Resistance modes \\
\hline \multirow[t]{4}{*}{$\beta$-lactams } & Penicillins (ampicillin) & Peptidoglycan biosynthesis & Hydrolysis \\
\hline & Cephalosporins (cephamycin) & & Efflux \\
\hline & Penems (meropenem) & & Altered target \\
\hline & Monobactams (aztreonam) & & \\
\hline \multirow[t]{5}{*}{ Aminoglycosides } & Gentamicin & Translation & Phosphorylation \\
\hline & Streptomycin & & Acetylation \\
\hline & Spectinomycin & & Nucleotidylation \\
\hline & & & Efflux \\
\hline & & & Altered target \\
\hline \multirow[t]{2}{*}{ Glycopeptides } & Vancomycin & Peptidoglycan biosynthesis & Reprogramming of peptidoglycan biosynthesis \\
\hline & Teicoplanin & & \\
\hline \multirow[t]{2}{*}{ Tetracyclines } & Minocycline & Translation & Monooxygenation \\
\hline & Tigecycline & & Efflux \\
\hline \multirow[t]{4}{*}{ Macrolides } & Erythromycin & Translation & $\begin{array}{l}\text { Altered target } \\
\text { Hydrolysis }\end{array}$ \\
\hline & Azithromycin & & Glycosylation \\
\hline & & & Phosphorylation \\
\hline & & & Efflux \\
\hline \multirow[t]{2}{*}{ Phenicols } & Chloramphenicol & Translation & $\begin{array}{l}\text { Altered target } \\
\text { Acetylation }\end{array}$ \\
\hline & & & Efflux \\
\hline \multirow{3}{*}{ Quinolones } & & & Altered target \\
\hline & Ciprofloxacin & DNA replication & Acetylation \\
\hline & & & Efflux \\
\hline Pyrimidines & Trimethoprim & $\mathrm{C} 1$ metabolism & $\begin{array}{l}\text { Altered target } \\
\text { Efflux }\end{array}$ \\
\hline \multirow{3}{*}{ Sulfonamides } & & & Altered target \\
\hline & Sulfamethoxazole & C1 metabolism & Efflux \\
\hline & & & Altered target \\
\hline
\end{tabular}




\section{Bacterial resistance and the environment}

The gastrointestinal system of humans and animals is ideal reservoirs for MDR development. Patients prescribed antibiotics in hospitals or domestic livestock fed with antibiotics are the highest risk factors for developing resistance. ${ }^{[18]}$ In the case of agricultural antibiotic usage, the drugs are administered at subtherapeutic doses to promote growth in cattle, swine, poultry, and fish. ${ }^{[35-38]}$ The dissemination of antibiotics such as $\beta$-lactams, colistin, macrolides, sulfonamides, trimethoprim, fluoroquinolones, and tetracyclines into the environment further increases the prevalence of MREs. ${ }^{[39-44]}$ Depending on their solubility and polarity, antibiotics, and their metabolites may be degraded by detergents or enzymes, aggregated with sewage sludge or released into river systems. ${ }^{[45]}$ Drugs present in sludge may enter agricultural systems when the sludge is used as fertilizer, while wastewater and surface water containing drugs enters the ecosystem via irrigation. Antibiotics fed to livestock may reenter the environment directly when recycled onto crops, soils, and detritus as manure. Veterinary drugs and their metabolites may directly enter water sources after being added with food into fish farms or hydroponics. ${ }^{[4]}$

A range of antibiotics have been shown to persist in the environment for months or even years. ${ }^{[46]}$ The macrolide antibiotic tylosin was found to be contaminating the U.S. water sources in 2013. ${ }^{[47]}$ Antibiotics may also be released into the environment during manufacturing. This is a particular problem for India and China, where antibiotics are produced for livestock on substantial scales and regulations may be less stringent. ${ }^{[1]}$ MDR bacteria, mobile MREs, or residual antibiotics can then be transferred back to humans through contaminated food. They may pass harmlessly through the human gut and back into sewage, although the commensal microflora colonizing the gut are given ample opportunity for horizontal gene transfer and thus resistance may develop in multiple resistant bacterial species. $^{[11,48]}$

\section{Global impacts of antibiotic resistance on human}

health

There is a clear correlation between the increase in antimicrobial resistance and the simultaneous increase in morbidity, mortality, and cost associated with disease therapy. ${ }^{[49]}$ Some of the major strains of bacteria of clinical importance, the diseases they cause, and their resistance to antibiotic drugs are summarized in Table 2 . Increases in morbidity and mortality are due to ineffective and delayed treatment choices. This is also true for diseases in which alternative antibiotics are expensive and cannot be feasibly administered. Another important consequence of antimicrobial resistance is the increase in the incidence of the disease. ${ }^{[62,63]}$ This is especially true and far more dangerous in the case of MDR organisms. The transfer of such MDR strains, particularly among the vulnerable (young, elderly, or immunocompromised individuals) may be fatal. ${ }^{[64]}$ Furthermore, the cost of medical care involved in the treatment of infectious diseases has significantly increased as a result of antibiotic resistance. For example, a 2009 report by the Centers for Disease Control and Prevention (CDC) revealed that the cost of hospitalization of a single

Table 2: A list of some clinically important bacteria, associated diseases, and susceptibility to conventional antibiotics

\begin{tabular}{|c|c|c|}
\hline Pathogen & Associated diseases & Antibiotic susceptibility \\
\hline A. baumannii & $\begin{array}{l}\text { Hospital-acquired pneumonia, ventilator-associated } \\
\text { pneumonia, bacteremia, meningitis, endocarditis, } \\
\text { urinary tract infections, wound/burn infections }\end{array}$ & $\begin{array}{l}\text { Resistance to } \beta \text {-lactams, cephalosporins, aminoglycosides, quinolones, and } \\
\text { carbapenems reported. Sensitive to sulbactam in combination with } \beta \text {-lactams }{ }^{[10]}\end{array}$ \\
\hline C. jejuni & Diarrhea, dysentery, enteritis & $\begin{array}{l}\text { Azithromycin and ciprofloxacin are typically used in treatment, resistance } \\
\text { against both of these drugs has been reported }{ }^{[50]}\end{array}$ \\
\hline C. difficile & Diarrhea, inflammatory bowel disease & $\begin{array}{l}\text { Low tolerance for most conventional antibiotics, though strains demonstrating } \\
\text { substantial resistance to fluoroquinolones are well documented }{ }^{[51]}\end{array}$ \\
\hline E. faecalis & $\begin{array}{l}\text { Endocarditis, septicemia, urinary tract infections, } \\
\text { meningitis }\end{array}$ & $\begin{array}{l}\text { Most strains resistant to a variety of aminoglycosides, } \beta \text {-lactams, macrolides, and } \\
\text { cephalosporins }{ }^{[52]} \text { Daptomycin, linezolid and ampicillin are used in treatment. } \\
\text { Ampicillin is used for treatment of resistant strains }\end{array}$ \\
\hline E. coli & $\begin{array}{l}\text { Urinary tract infections, neonatal meningitis, } \\
\text { gastroenteritis, bowel necrosis, pneumonia, septicemia, } \\
\text { peritonitis, hemolytic-uremic syndrome (E. coli 0157:H7) }\end{array}$ & $\begin{array}{l}\text { Depending on the strain, } E \text {. coli demonstrate resistance to a range of antibiotics. } \\
\text { Fluoroquinolones, azithromycin, and rifaximin are typically used in treatment }{ }^{[53]}\end{array}$ \\
\hline H. pylori & Abdominal pain, acute gastritis, nausea, peptic ulcers & $\begin{array}{l}\text { Increasing resistance to a range of antibiotics including clarithromycin, } \\
\text { clarithromycin metronidazole, tetracycline, amoxicillin, rifabutin, and } \\
\text { fluoroquinolones. }{ }^{[5,55]} \text { Quadruple therapies adding bismuth colloids are used for } \\
\text { treatment of highly resistant strains }\end{array}$ \\
\hline K. pneumoniae & $\begin{array}{l}\text { Pneumonia, bronchitis, urinary tract infections, } \\
\text { meningitis, septicemia }\end{array}$ & $\begin{array}{l}\text { A wide range of reported resistance, mostly aminoglycosides, fluoroquinolones, } \\
\text { tetracyclines, and trimethoprim. Treatments involve combination antibiotics } \\
\text { of } \beta \text {-lactams with beta-lactamase inhibitors. Carbapenem and colistin-resistant } \\
\text { strains often require additional therapies }{ }^{[56]}\end{array}$ \\
\hline M. tuberculosis & Pulmonary tuberculosis, spinal tuberculosis, meningitis & $\begin{array}{l}\text { Early } \beta \text {-lactams demonstrate no activity against } M \text {. tuberculosis. Current } \\
\text { therapies focus on dose combinations of isoniazid, pyrazinamide, rifampin and } \\
\text { ethambutol. Resistance to these drugs has been well-documented }{ }^{[57,58]}\end{array}$ \\
\hline N. gonorrhoeae & $\begin{array}{l}\text { Gonorrhea, dysuria, meningitis, urethritis, endocarditis, } \\
\text { conjunctivitis, pharyngitis, dermatitis }\end{array}$ & Resistance to azithromycin, tetracycline, ceftriaxone, and cefixime reported ${ }^{[59]}$ \\
\hline P. mirabilis & Urinary tract infections, urinary calculus & $\begin{array}{l}\text { Generally susceptible to most antibiotics. Tetracycline and nitrofurantoin } \\
\text { have proved ineffective, with resistance noted against ampicillin and } \\
\text { extended-spectrum cephalosporins }{ }^{[60]}\end{array}$ \\
\hline P. vulgaris & $\begin{array}{l}\text { Hospital-acquired pneumonia, ventilator-associated } \\
\text { pneumonia, urinary tract infections, urinary calculus }\end{array}$ & $\begin{array}{l}\text { Susceptible to a range of antibiotics, including ceftazidime, ciprofloxacin, } \\
\text { meropenem, and combination therapies with ampicillin/sulbactam or } \\
\text { piperacillin/tazobactam. Resistance to ampicillin and first-generation } \\
\text { cephalosporins reported }{ }^{[61]}\end{array}$ \\
\hline
\end{tabular}

A. baumannii=Acinetobacter baumannii, C. jejuni=Campylobacter jejuni, C. difficile=Clostridium difficile, E. faecalis=Enterococcus faecalis, E. coli=Escherichia coli, H. pylori=Helicobacter pylori, K. pneumoniae=Klebsiella pneumoniae, . tuberculosis=Mycobacterium tuberculosis, N. gonorrhoeae=Neisseria gonorrhoeae, P. mirabilis=Proteus mirabilis, $P$. vulgaris=Proteus vulgaris 
XDR-TB patient in the USA is approximately $\$ 483,000$, which is double the cost of treating a MDR-TB patient. ${ }^{[65]}$ Recently, the US Congress has announced a total of US $\$ 463$ million funding for research into antibiotic resistance. ${ }^{[66]}$

Drug resistance in European hospitals is monitored by the European Centre for Disease Control and the European Medicines Agency. Europe now faces at least 400,000 cases and 25,000 hospitalized-patient mortalities per year as a result of MDR bacteria. Extra hospital days are estimated at 2.5 million per year and productively losses have exceeded $€ 1.5$ billion each year since 2007. ${ }^{[61,67]}$ Surging resistance through ESBLs in Europe has rendered most third-generation cephalosporins (cefotaxime, ceftazidime, and ceftriaxones) ineffective for the treatment of multiple Gram-positive and Gram-negative bacterial infections. ${ }^{[68]}$

Vancomycin-resistant enterococci (VRE) are a problematic cause of urinary tract infections (UTIs), bacteremia, meningitis, intra-abdominal, and neonatal infections in the Europe and the USA due to their resistance to a variety of antimicrobials. First identified as an outbreak of Enterococcus faecium and Enterococcus faecalis infections resistant to vancomycin, ${ }^{[69]}$ the resistance was found to be due to the plasmid-borne genes $v a n A$, vanB, and vanC. ${ }^{[70,71]}$ E. faecalis is the predominant enterococci shown to resist vancomycin and the cause of $90 \%$ of nosocomial infections in patients in the USA. ${ }^{[72]}$ Linezolid is currently the last antibiotic available for the treatment of VRE infections. Of concern, linezolid-resistant VRE clinical isolates have been identified and further therapeutic options are desperately required. ${ }^{[73-75]}$

MRSA is resistant to $\beta$-lactams, ${ }^{[76]}$ cephalosporins, carbapenems, and aminoglycosides. ${ }^{[7]}$ Resistance to the $\beta$-lactam structure arises due to the presence of plasmids containing the mecA and mecC resistance genes. ${ }^{[34,78]}$ The proportion of nosocomial S. aureus infections identified as MRSA cases vary between $15 \%$ and $75 \%$ among reports from different hospitals. ${ }^{[79-81]}$ Overall, the incidence of MRSA cultured from patients in the USA increased from 3\% of Staphylococcus infections in 1980 to more than $60 \%$ at the end of the millennia. ${ }^{[82]}$ Less than $20 \%$ of MRSA in the USA are susceptible to commercial fluoroquinolones. ${ }^{[72]}$ The CDC in the USA reported ciprofloxacin resistance in MRSA increasing from less than $5 \%$ of patients to more than $80 \%$ within a year following the clinical approval of ciprofloxacin. ${ }^{[82]}$ Compounding the problem, MRSA strains that are less susceptible to vancomycin have been isolated from clinical samples, ${ }^{\left[{ }^{[3]}\right.}$ with some studies revealing a high rate of vancomycin resistant E. faecalis among patient populations. ${ }^{[84]}$

Another bacterial strain of particular threat to human health is Klebsiella pneumoniae, an opportunistic Gram-negative pathogen that causes nosocomial and community-acquired infections including septicemia, bacteremia, UTIs, pneumonia, wound infections, ${ }^{[84,85]}$ and ankylosing spondylitis. ${ }^{[86]} \beta$-lactamases encoded by $A m p C$ and related genes were found to reduce bacterial sensitivity to a wide spectrum of $\beta$-lactam drugs such as cephalosporins. ${ }^{[87-89]}$ This was followed by the detection of transmissible carbapenem-hydrolyzing $\beta$-lactamase enzymes, denoted $K$. pneumoniae carbapenamase (KPC) 1, 2, and 3. ${ }^{[90-92]}$ The outcome for patients infected with highly resistant KPC strains is poor, being strongly associated with mortality, ${ }^{[93,94]}$ especially for those who contract the hypervirulent variant that produces serious infections. ${ }^{[95]}$ More recently, an XDR K. pneumoniae outbreak in China revealed a suite of resistant genes in K. pneumoniae from clinical isolates conferring resistance to $\beta$-lactams, quinolones, aminoglycosides, chloramphenicol and fosfomycin, or to different $\beta$-lactam/inhibitor profiles. ${ }^{[96]}$ Colistin has now become the final resort for treatment in patients infected with resistant $K$. pneumoniae. However, the plasmid-borne $m c r-1$ gene provides resistance to this antibiotic and its mobile properties also lead to interspecies transfer among Gram-negative bacteria. ${ }^{[97]}$ This troubling connection between extensive/total resistance, transferability of plasmid-borne resistance genes and hypervirulence in K. pneumoniae is likely to have persistent and far-reaching consequences on global human health. Moreover, it underscores the need for research into the discovery and design of novel chemotherapeutic agents or combinatorial approaches to antimicrobial therapy.

\section{DISCOVERY OF NEW ANTIBIOTICS: RECENT TRENDS}

As discussed, the discovery of new antibiotics with novel mechanisms of action severely declined during the late 1960s. The last novel class of antibiotic to be discovered before the new millennium was in 1968 with most subsequent antibiotics being modified versions of previously discovered antibiotic classes. ${ }^{[98]}$ The development of new antibacterial agents has decreased substantially in recent decades despite the current demand for new antimicrobial drugs. The cost of research and development of antimicrobial agents has risen to a level that yield a low (and thus unattractive) profitability of pursuing new drug development within the pharmaceutical industry. ${ }^{[99]}$ This is exacerbated by the length of duration ( 8 years) that is required in order for new agents to pass Phase 1 clinical testing and reach product launch. ${ }^{[98]}$ The number of newly approved antibacterial agents has decreased over a 20-year period from 1983 to 1992, and even more so between 1992 and 2017 [Table 3].

\section{Drugs in development and clinical trials}

The current number of antimicrobials in research and development is simply not sufficient for controlling the evolution of MDR bacteria. All drugs in development must undergo extensive human trials and any success goes unpublished until the agent is approved for human use. ${ }^{[100]}$ The Phase 3 development trial stage assesses the effectiveness of the drug for clinical use, while reevaluating its efficacy and safety from Phase 2. It is common for antimicrobials in Phase 3 to be rejected. In 2010, The Centre for Medicines Research estimated that $50 \%$ of Phase 3 drugs were unsuccessful. ${ }^{[101]}$ Antibiotic drug formulations that are currently within Phase 3 development are shown in Table 4.

Novel antimicrobials may be delayed more than a decade after discovery, and only one in five drugs ever reach the first human trials in Phase 1. ${ }^{[101]}$ Furthermore, approved drugs are often prone to several caveats for the treatment of a variety of infections. For example, ceftolozane administered with tazobactam (trading as Zerbaxa) was approved for human use in December 2014. The drug exhibits specific activity against Pseudomonas aeruginosa in patients with hospital-acquired and ventilator-associated pneumonia. Post-marketing surveillance of Zerbaxa showed no activity against anaerobic pathogens and limited activity as a Gram-positive antimicrobial agent. Only limited activity is observed towards pathogenic Staphylococcus spp. and Clostridium difficile spp. populations in patients by this formulation. ${ }^{[16]}$ The combination of ceftazidime with the novel $\beta$-lactamase inhibitor avibactam (sold commercially as Avycaz) was approved more recently in February 2015. The drug is administered in combination with avibactam to produce an additive effect in patients infected with Gram-negative bacteria. Diseases commonly treated by Avycaz include pyelonephritis and complicated UTIs. Unlike Zerbaxa, Avycaz is active against a broad spectrum of Enterobacteriaceae but is still compromised by metallo- $\beta$-lactamases (class B $\beta$-lactamases). In particular, Haemophilus moraxella, Neisseria spp., and Acinetobacter spp. are unaffected by this drug. ${ }^{[117]} \mathrm{New}$ antibiotics are often active across limited spectrums, expensive, and may be ineffective against certain strains within several years. Indeed, resistance to Avycaz has already been reported. ${ }^{[118]}$ 
Table 3: History of antibacterial drug approvals to the pharmaceutical market (in any country) since 1983. Time intervals are 5-year periods. List does not include antibiotics released as combination therapies (e.g., ampicillin/sulbactam) for antibiotic components approved prior to 1983

\begin{tabular}{|c|c|c|c|}
\hline Year introduced & Antibiotic & Antibiotic class & Total \\
\hline \multirow[t]{9}{*}{ 1983-1987 } & Cefonicid, cefotetan & Second generation cephalosporin & 17 \\
\hline & Cefmenoxime, ceftazidime, ceftazoxime, cefpiramide, cefixime & Third generation cephalosporin & \\
\hline & Norfloxacin, ofloxacin, ciprofloxacin & Quinolone & \\
\hline & Temocillin, ticarcillin & $\beta$-lactam & \\
\hline & Imepinem & Carbapenem & \\
\hline & Mupirocin & Protein synthesis inhibitor & \\
\hline & Aztreonam & Monobactam & \\
\hline & Roxithromycin & Macrolide & \\
\hline & Rifaximin & Ansamycin & \\
\hline \multirow[t]{9}{*}{ 1988-1992 } & Azithromycin, clarithromycin, midecamycin & Macrolide & 20 \\
\hline & Flomoxef & Oxacepham & \\
\hline & Isepamicin, arbekacin & Aminoglycoside & \\
\hline & Rifapentine & Rifamycin & \\
\hline & Teicoplanin & Glycopeptide & \\
\hline & Cefprozil, loracarbef & Second generation cephalosporin & \\
\hline & Cefpodoxime, cefdinir, cefetamet, ceftibuten & Third generation cephalosporin & \\
\hline & Cefpirome & Fourth generation cephalosporin & \\
\hline & Moxifloxacin, enrofloxacin, lomefloxacin, fleroxacin, rufloxacin & Quinolone & \\
\hline \multirow[t]{4}{*}{ 1993-1997 } & Brodimoprim & Folate synthesis inhibitor & 6 \\
\hline & Dirithromycin & Macrolide & \\
\hline & Levofloxacin, nadifloxacin, sparfloxacin & Quinolone & \\
\hline & Cefepime & Fourth generation cephalosporin & \\
\hline \multirow[t]{3}{*}{ 1998-2002 } & Quinupristin/dalfopristin & Streptogramin & 4 \\
\hline & Linezolid & Oxazolidinone & \\
\hline & Telithromycin & Ketolide & \\
\hline \multirow[t]{3}{*}{ 2003-2007 } & Daptomycin & Lipopeptide & 3 \\
\hline & Tigecycline & Glycylcycline & \\
\hline & Doripenem & Carbapenem & \\
\hline \multirow[t]{5}{*}{ 2008-2012 } & Telavancin & Lipoglycopeptide & 5 \\
\hline & Ceftaroline & Fifth generation cephalosporin & \\
\hline & Fidaxomicin & Macrocyclic & \\
\hline & Bedaquiline & Diarylquinolone & \\
\hline & Telavancin & Lipoglycopeptide & \\
\hline \multirow[t]{3}{*}{ 2013-2017 } & Tedizolid & Oxazolidinone & 5 \\
\hline & Ceftobiprole, ceftolozane & Fifth generation cephalosporin & \\
\hline & Dalbavancin, oritavancin & Lipoglycopeptide & \\
\hline
\end{tabular}

Table 4: Antibiotic drugs or drug combinations currently in Phase 3 development. The PEW Charitable Trusts. ${ }^{[102]}$

\begin{tabular}{|c|c|c|}
\hline Drug name & Drug class & References \\
\hline Delafloxacin & Fluoroquinolone & [103] \\
\hline Siderophore & Cephalosporin & {$[105]$} \\
\hline Eravacycline & Tetracycline & [107] \\
\hline Lefamulin & Pleuromutilin & [108] \\
\hline Imipenam and cilistatin + relbactam & Carbapenem and dehydropeptidase inhibitor + novel $\beta$-lactamase inhibitor & [109] \\
\hline Sodium fusidate (Taksta) & Fusidane & [112] \\
\hline Carbavance (meropenem + vaborbactam) & Meropenem + novel boronate $\beta$-lactamase inhibitor & [113] \\
\hline Plazomicin & Aminoglycoside & [114] \\
\hline Solithromycin & Macrolide (fluoroketolide) & [115] \\
\hline
\end{tabular}

\section{ALTERNATIVES: NEW SOURCES OF ANTIBIOTIC THERAPIES}

\section{Vaccination used in conjunction with antibiotics}

Antibiotics alone are not a sustainable solution for the treatment of bacterial infections. Medicinal alternatives are available that show effective antimicrobial activity where antibiotics are not effective, or that work to enhance antibiotic activity in vivo. Vaccines provide a prophylactic solution to treatment. ${ }^{[19]}$ They may provide life-long immunity and may cost significantly less than the daily dose of some drugs. However, the advantage of using antibiotics is that they exhibit a broad-spectrum of activity, which is incredibly useful for treating infections where the causative agent is unknown. Antibiotics also maintain an essential role in the treatment of infections for cancer patients and surgical-associated infections. ${ }^{[120]}$ In this regard, vaccines and antibiotics appear to demonstrate complementary roles rather than 
redundancy, and it is difficult to scale their benefits to human health. For example, herd immunity comes when a suitable portion of a population is immunized, depending on the pathogen. ${ }^{[121]}$ This, incidentally, reduces the number of patients who require antibiotics. ${ }^{[120]}$ For example, a pneumococcal conjugate vaccine can reduce the usage of macrolides in hospitals for primary and second-line treatment, as well as diminish the incidence of invasive $S$. pneumoniae disease in both children and adults. ${ }^{[120,122]}$ However, MDR clones are beginning to emerge ${ }^{[122]}$ which threaten the success of vaccinations. This has already been observed in hospitalized children. ${ }^{[123]}$

\section{Bacteriophage therapy}

Bacteriophages present another alternative in the treatment of antibiotic resistant bacteria. Infecting and killing of Shigella spp. with bacteriophage was first observed long before Fleming would first observe the effects of penicillin. ${ }^{[124]}$ Human phage therapy studies have shown bacteriophage are effective at treating patients for a variety of clinically important bacteria including Staphylococcus, Klebsiella, and Pseudomonas species and these therapies are already used effectively in some Eastern European countries. ${ }^{[125,126]}$ The properties of bacteriophage seem to favor their clinical use (safety, low dosage required, etc.), although their use in Western medicine is yet to be widely accepted. Much of the original work on medicinal bacteriophage therapy does not comply with modern drug trial protocols. Furthermore, the majority of follow-up research was conducted in Eastern Europe and not translated into English. Despite this, Western medicine may view bacteriophage therapy as a useful alternative to antibiotics in the near future. Recent studies have identified bacteriophage therapies as successful and cost-effective for the treatment of antibiotic-resistant bacterial infections including MRSA and $P$. aeruginosa. ${ }^{[127,128]}$ This treatment modality is promising for some bacterial pathogens, although much more research is required in this field.

\section{TRADITIONAL MEDICINES AND PLANT-DERIVED ANTIBIOTIC THERAPIES}

Traditional healing systems have relied upon medicinal plants for the treatment of bacterial infections for many centuries. Approximately, 80\% of the developing world relies on traditional medicines derived from medicinal plants as their primary health-care modality. ${ }^{[129,130]}$ A survey by the United Nations Conference on Trade and Development reported that more than $33 \%$ of total drugs produced by industrialized nations are plant derived and the WHO have recorded the names of over 20,000 species of medicinal plants with a variety of potential uses. ${ }^{[131]}$ Medicinal plants are often less expensive, safer to use in terms of side effects and more readily available in comparison to their synthetic counterparts. Furthermore, they are abundant in active compounds that have antimicrobial activity. These bioactive substances (phytochemicals) include tannins, alkaloids, carbohydrates and glycosides, terpenoids, steroids, flavonoids, and coumarins. ${ }^{[130]}$ These compounds are of particular clinical value because their bioactivity generally does not confer resistance. ${ }^{[132]}$ At the time of this review, no report claims to have observed bacteria developing resistance to plant-based antimicrobials (PBAs).

Most bioactive PBAs are phenol derivatives, controlling bacterial growth by altering their membrane permeability or reducing the $\mathrm{pH}$. However, their activity is generally weak and is often non-specific. ${ }^{[133]}$ Plants generally produce these products in relatively high concentrations for self-protection against pathogens although exceptions in nature have been observed. ${ }^{[132]}$ Polyalthea nemoralis Aug. DC., a Chinese medicinal plant, produces a highly-specific pyrithione which inhibits specific fungi and bacteria. ${ }^{[134]}$ Structurally, many antibiotic phytochemicals resemble clinical antibiotics. Quinine, isolated from the bark of the cinchona tree, is a metal chelator with a high activity against Plasmodium spp. in the treatment of malaria. Fluoroquinolones were developed from nalidixic acid, a precursor of quinines. ${ }^{[135]}$ Some cases of target specificity among PBAs have been reported. Coumarins have a high activity against $S$. aureus while demonstrating no activity against Gram-negative bacteria. ${ }^{[132]}$ A significant interaction relevant for clinical infections is the bactericidal effects on MRSA demonstrated by a variety of PBAs. They include but are not limited to: grape seed extract, screwbean leaf extract, peanut tree leaf extract, peanut tree bark extract, sandpaper fig bark extract, hibiscus bark extract, and Queensland poplar extract. ${ }^{[136,137]}$ The reports of anti-Staphylococcus plant antimicrobials in recent studies appear to be motivated by the urgent requirement for new anti-Staphylococcal medicines. Studies suggest PBAs have a variety of applications against many pathogens. Despite this, plant compounds remain under-represented as clinical antibiotic therapies.

Plants remain central to several traditional medical practices including Ayurveda (a traditional Indian medicinal system) and traditional Chinese medicine (TCM). Numerous Indian medicinal plants used in folkloric medicine possess significant antimicrobial properties. ${ }^{[131]}$ An investigation into fifty popular medicinal plants of 26 different families reported that nearly $72 \%$ of the plants displayed antimicrobial activity against both Gram-positive and Gram-negative bacteria. ${ }^{[131]}$ Despite these studies, the vast majority of the plant species globally are yet to be researched for therapeutic purposes. Multiple studies have reported that Indian medicinal plants possess relatively high levels of antimicrobial activity. ${ }^{[129,138,139]}$ Similar studies have also been conducted on plants commonly used in TCM. For example, plants used in TCM for the treatment of gastric ulcers are highly effective against Helicobacter pylori, a causative factor in peptic/gastric ulcer disease. ${ }^{[140]}$ While the majority of the pharmacognostic studies originate from Asia; researchers have also reported the effectiveness of numerous native traditional medicinal plants globally, including studies from the USA, ${ }^{[141]}$ South Africa, ${ }^{[142,143]}$ Australia, ${ }^{[86,144-147]}$ and from Trinidad and Tobago in the Caribbean. ${ }^{[148]}$

Over recent years, Western medicine has begun to acknowledge the benefits of traditional medical plants. A recent report by the WHO described medicinal plants as one of the best potential sources of new drugs. ${ }^{[130]}$ There are numerous examples of compounds isolated from plants that have been effective as antimicrobial agents. Artemisinin, extracted from the plant Artemisia annua L., possesses antimalarial properties and is responsible for saving millions of lives globally ${ }^{[149]}$ Resveratrol, which is found in grapes and Itadori plants ${ }^{[150]}$ exerts bacteriostatic effects on multiple Gram-positive and Gram-negative bacteria. ${ }^{[151,152]}$ Berberis aristata DC. and Berberis asiatica Roxb. ex DC. contain the alkaloid berberine, ${ }^{[153]}$ which possesses antibacterial properties. ${ }^{[154]}$ However, of the approximately 422,000 plant species worldwide, it is estimated that only a small portion $(1 \%-10 \%)$ of the estimated total number of herbal medicines derived from these species have been examined for antimicrobial properties.

Despite a substantial increase in the number of publications on antibacterial plants and compounds isolated from them in recent years, there are still only relatively few plant-derived drugs in clinical use. This may be because plant compounds often require complex combinational effects between components to synergize the activity of the bioactive compound. Therefore, examination of combinations of plant compounds, or of plant compounds in combination with conventional antibiotics may be a more fruitful line of research.

\section{COMBINATIONAL ANTIMICROBIAL CHEMOTHERAPIES}

There are several ways in which antimicrobial resistance can be prevented, reduced and/or reversed and using medicinal plant extracts with intrinsic 
antimicrobial properties has proven to be a relatively effective method. However, a combinational approach that allows synergistic interaction between plant extracts and conventional antibiotics is arguably the most effective method to combat antibacterial resistance. ${ }^{[155]}$ There is already evidence for the enhancement of conventional antibiotics by acting synergistically with plant-derived compounds. The combination of $\beta$-lactams with $\alpha$-mangostin isolated from mangosteen fruit, ${ }^{[156,157]}$ or with quercetin or kaempferol from various fruits, vegetables, and grains, ${ }^{[158]}$ substantially increase the efficacy of the therapy in $\beta$-lactam resistant bacterial strains. It is likely that the mangosteen derived components of these combinations may inhibit the bacterial $\beta$-lactamase enzyme, thus reactivating the antibiotic. Even plant-derived compounds which themselves have been found to possess antibiotic properties (e.g., berberine) ameliorate P. aeruginosa aminoglycoside resistance. ${ }^{[159]}$ Therefore, the ability of plant compounds to "re-purpose" conventional antibiotics in the treatment of microbial infections may significantly impact global health in terms of combatting resistant pathogenic microorganisms. Further examples of similar combinations are shown in Table 5.

Synergistic evaluation studies examine combinations of two or more drugs in the hopes of achieving an enhanced overall effect which is substantially greater than the sum of their individual parts. ${ }^{[164]}$ Recently, combination therapy has gained widespread recognition, especially in the field of infectious disease. According to the WHO, combinational therapy is preferred over monotherapy in multiple life-threatening infectious diseases such as malaria, tuberculosis, and HIV/AIDS due to its ability to target multiple facets of a disease and to curb resistance. ${ }^{[165]}$ Antimicrobial natural product combination drugs have become a research priority due to several factors, including an economical advantage over conventional methods of drug discovery. In comparison to developing a new drug which requires years of extensive testing, an aim of combination therapy is to restore an existing drug to a state of significantly reduced resistance. Restoring activity to conventional antibiotics using combinations would enable the drug to reach clinical usage much more rapidly and at a much lower development cost as the bioactive component of the combination has already been evaluated through extensive clinical trials. Thus, the testing requirements are less rigorous. Further advantages of synergistic interactions are increased efficiency, reduced side effects, increased stability and bioavailability, and the need for lower doses in comparison to synthetic alternatives. ${ }^{[155]}$ Plant extract/antibiotic combinations not only contribute to and enhance the overall antimicrobial effect, but can also act as resistance modifying/modulating agents. Some crude plant extracts damage the cytoplasmic membrane of resistant bacteria and cause loss of intracellular components. A recent study reported that multiple Salvia spp. and Matricaria recutita had synergistic effects with oxacillin, greatly enhancing its efficacy. ${ }^{[166]}$ The exact mechanism for the reduction in antibiotic resistance by those extracts is still unclear. However, the authors of that study postulated that it was due to a structural change within the resistant bacteria. The plant extracts, coupled with the action of oxacillin, potentially caused significant perturbation of the cell membrane.

The word "synergy" implies that the resulting effect of a combination is significantly greater than the sum its individual parts. ${ }^{[164,167]}$ However, a combination of two antimicrobial agents may also be defined using other categories such as additive, noninteractive, and antagonistic. An "additive" effect is when substances added together will improve or increase efficacy, albeit not to the extent of a synergistic interaction. For "non-interactive" (or indifferent) combinations, the individual components of the combination show neither additive nor antagonistic effects. "Antagonism" is when a combination of agents produce an overall effect lesser that a sum of their individual effects (i.e., the two drugs are reducing the efficacy of each other). There are several interpretations on how synergistic interactions can and should be quantified among researchers. However, the most recent and widely accepted method is the use of fractional inhibitory concentration index ( $\Sigma$ FIC) (derived from minimum inhibitory concentration $[\mathrm{MIC}])$ and isobologram analysis [Figure 3a] in the interpretation of synergistic results. ${ }^{[168,169]} \mathrm{A}$ synergistic result would have a $\Sigma$ FIC $\leq 0.5$; an additive is $\Sigma$ FIC $>0.5-1.0$,

Table 5: Examples of plant-based antimicrobials used in combination with antibiotics demonstration successful antimicrobial activity against clinically important bacteria in vitro

\begin{tabular}{|c|c|c|c|}
\hline Plant studied & PBAs + Antibiotic & $\begin{array}{l}\text { Bacteria } \\
\text { treated }(\mathrm{FICl})\end{array}$ & Comments \\
\hline Berberidaceae spp. & Berberine + azithromycin & MRSA (0.375) & $\begin{array}{l}\text { MICs of the berberine + azithromycin combination against MRSA reduced } \\
\text { by } 50 \%-96.9 \% \text { compared to the agents used alone }{ }^{[160]}\end{array}$ \\
\hline Berberidaceae spp. & $\begin{array}{l}\text { 8-acetonyl-dihydroberbine } \\
+ \text { levofloxacin }\end{array}$ & MRSA (0.188) & $\begin{array}{l}\text { 8-acetonyl-dihydroberbine possibly exhibits a greater ability to permeate the } \\
\text { membrane of MRSA than berberine }{ }^{[160]}\end{array}$ \\
\hline S. tetrandra & Tetrandrine + cefazolin & MRSA $(0.250)$ & $\begin{array}{l}\text { MICs of the tetrandrine + cefazolin combination against MRSA reduced by } \\
75 \%-94 \% \text { compared to the agents used alone }{ }^{[161]}\end{array}$ \\
\hline S. tetrandra & $\begin{array}{l}\text { Demethyltetrandrine }+ \\
\text { cefazolin }\end{array}$ & MRSA (0.188) & $\begin{array}{l}\text { MICs of the demethyltetrandrine + cefazolin combination against MRSA } \\
\text { reduced by } 50 \%-94 \% \text { compared to the agents used alone }{ }^{[161]}\end{array}$ \\
\hline T. broussonetii & $\begin{array}{l}\text { Carvacrol/borneol }+ \\
\text { pristinamycin }\end{array}$ & K. pneumoniae $(0.500)$ & $\begin{array}{l}\text { Carvacol shown to destabilize the cytoplasmic membrane of bacteria by } \\
\text { reducing } \mathrm{pH}^{[162]}\end{array}$ \\
\hline T. maroccanus & $\begin{array}{l}\text { Carvacrol/thymol + } \\
\text { ciprofloxacin }\end{array}$ & $\begin{array}{l}\text { V. cholerae }(0.140) \text {, } \\
\text { K. pneumoniae }(0.37) \text {, } \\
\text { S. aureus }(0.26), P . \\
\text { aeruginosa }(0.15)\end{array}$ & $\begin{array}{l}\text { Synergy demonstrated against both Gram-positive and Gram-negative } \\
\text { bacteria }^{[162]}\end{array}$ \\
\hline T. maroccanus & $\begin{array}{l}\text { Carvacrol/thymol + } \\
\text { gentamycin }\end{array}$ & P. aeruginosa $(0.180)$ & $\begin{array}{l}\text { T. maroccanus extract }(89.15 \%) \text { contains a greater proportion of carvacrol } \\
\text { than Thymus broussonetii extract }(21.31 \%) \text {, suggesting T. maroccanus may } \\
\text { demonstrate greater antimicrobial activity }{ }^{[162]}\end{array}$ \\
\hline Z. multiflora & $\begin{array}{l}\text { Thymol/carvacrol + } \\
\text { vancomycin }\end{array}$ & S. aureus $(0.185)$ & $\begin{array}{l}\text { MICs of thymol/carvacrol + vancomycin against } S \text {. aureus was lowered from } \\
1 \mu \mathrm{g} / \mathrm{mL} \text { to } 0.125 \mu \mathrm{g} / \mathrm{mL} \text { when used in combination }{ }^{[163]}\end{array}$ \\
\hline Z. multiflora & $\begin{array}{l}\text { Thymol/carvacrol + } \\
\text { vancomycin }\end{array}$ & $\operatorname{MRSA}(0.320)$ & First study to report the synergistic effects of $Z$. multiflora against MRSA ${ }^{[163]}$ \\
\hline
\end{tabular}

S. tetrandra=Stephania tetrandra, T. broussonetii=Thymus broussonetii, T. maroccanus=Thymus maroccanus, $Z$. multiflora=Zataria multiflora,

S. aureus=Staphylococcus aureus, MRSA=Methicillin-resistant $S$. aureus, K. pneumoniae=Klebsiella pneumoniae, V. cholerae $=$ Vibrio cholerae,

$P$. aeruginos $a=P$ seudomonas aeruginosa, $\mathrm{MICs}=$ Minimum inhibitory concentrations, $Z$. multiflora=Zataria multiflora, $\mathrm{PBAs}=\mathrm{Plant}-\mathrm{based}$ antimicrobials,

$\mathrm{FIC}=$ fractional inhibitory concentration 
noninteractive is $\Sigma$ FIC $>1.0-\leq 4.0$, and antagonistic is $\Sigma$ FIC $>4.0$. Examples of the effects of plant extracts combined with oxacillin treatment of a resistant bacterial strain are shown in Table 6.

\section{Synergy: The future of antimicrobial studies?}

Combinational therapies may improve the activity of weak antimicrobials against bacteria [Figure 3b]. Antibiotic combinations for the treatment of resistant infections have already been reported to be effective. One drug may neutralize or overwhelm the bacterial resistance mechanisms, repurposing the antibiotic drug by increasing its efficacy. Perhaps the best-known example of antibiotic synergy is the combination of clavulanic acid (a fungal-derived inhibitor of $\beta$-lactamase enzymes) with $\beta$-lactam antibiotics. ${ }^{[170]}$ In response to the misuse of $\beta$-lactam antibiotics over an extended period, many bacterial strains have evolved to produce $\beta$-lactamase enzymes which cleave the $\beta$-lactam ring structure of these antibiotics, rendering them ineffective. Clavulanic acid is a weak $\beta$-lactam with negligible intrinsic antimicrobial activity on its own despite sharing a similar $\beta$-lactam ring with other $\beta$-lactam antibiotics. The similarity in chemical structure allows the molecule to bind $\beta$-lactamase irreversibly and act as an inhibitor of the enzyme. An antibiotic chemotherapy named Augmentin $^{\odot}$ (combination of amoxicillin and potassium clavulanate) is formulated to take advantage of these synergistic combinational effects

Table 6: Interactions of plant extracts and oxacillin in effect on methicillin-resistant Staphylococcus epidermidis. Adapted from Chovanova et al, 2013 ${ }^{[166]}$

\begin{tabular}{lcccl}
\hline Plant extract & FIC A & FIC B & FIC & Interpretation \\
\hline S. fruticosa & 0.03 & 0.17 & 0.20 & Synergistic \\
S. officinalis & 0.05 & 0.09 & 0.14 & Synergistic \\
S. sclarea & 0.06 & 0.09 & 0.15 & Synergistic \\
A. tinctoria & 0.12 & 0.47 & 0.59 & Additive \\
C. nobile & 0.13 & 0.41 & 0.54 & Additive \\
M. recutita & 0.06 & 0.12 & 0.18 & Synergistic \\
T. argyophyllum & 0.26 & 0.53 & 0.79 & Additive \\
T. parthenicum & 0.24 & 0.51 & 0.75 & Additive \\
\hline
\end{tabular}

FIC A: MIC of substance A tested in combination/MIC of substance A tested alone, FIC B: MIC of substance B in combination/MIC of substance B tested alone, FIC=FIC A + FIC B. A=Oxacillin, B=Plant extract. $S$. fruticosa=Salvia fruticosa, S. officinalis=Salvia officinalis, S. sclarea=Salvia sclarea, A. tinctoria=Anthemis tinctoria, C. nobile=Chamaemelum nobile, $M$. recutita=Matricaria recutita, T. argyophyllum=Tanacetum argyophyllum, T. parthenicum=Tanacetum parthenicum, MICs=Minimum inhibitory concentrations, FIC $=$ Fractional inhibitory concentration and has effectively repurposed $\beta$-lactam antibiotics for use against $\beta$-lactam resistant bacteria. The combination of $\beta$-lactam antibiotics such as amoxicillin with $\beta$-lactam inhibitors such as clavulanic acid has been shown to be substantially more effective against Myobacterium tuberculosis than amoxicillin alone. ${ }^{[171]}$ Furthermore, clavulanic acid in combination with ampicillin, cephalothin, cephaloridine, or cefamandole is proven to act synergistically (reduced MIC and minimal bactericidal concentration) against $\beta$-lactamase-producing $S$. aureus and Enterobacteriaceae. ${ }^{[170]}$ There is enough evidence to suggest that the $\beta$-lactamase inhibitor may bind irreversibly, contributing to the overall efficacy of the antibiotic component of the combination. ${ }^{[170]}$

Microbes have also developed numerous other methods to resist antibiotics. Perhaps the most common method is through the use of MDR pumps. These efflux pumps are encoded chromosomally and utilized to rapidly remove antibiotics that have entered the bacterial cells, thus rendering them resistant to the effects of the antibiotic. ${ }^{[172,173]}$ A single pump can allow the bacteria to escape various types of antimicrobials. If the actions of the pumps are inhibited, then the intracellular concentration of antibiotic will increase, allowing the treatment to once again be effective. Interestingly, many plants possess MDR pump inhibitors to enhance the activity of their own natural antimicrobial compounds. Such MDR pump inhibitors become great tools when used in combination with some previously ineffective/resistance-prone antibiotic compounds. ${ }^{[172]}$ For example, synergistic activities have been reported for several plant tannins/conventional antibiotic combinations against both resistant and sensitive strains of Acinetobacter baylyi. ${ }^{[174]}$ Ellagic acid and tannic acid were particularly effective potentiators of several antibiotics, with approximately 4 -fold increases in potency against novobiocin, chlorobiocin, coumermycin, fusidic acid, and rifampicin compared to the antibiotics alone. Interestingly, neither ellagic acid nor tannic acid had appreciable antibacterial activity on their own. In contrast, neither of these tannins significantly potentiated the activity of tetracycline. That study also reported that the synergistic action of ellagic acid and tannic acid was due to the inhibition of an MDR efflux pump.

As well as the development of efflux pumps, bacteria may also become resistant to antibiotic action by target-site modification (preventing the binding of antibiotic) and by drug inactivation. ${ }^{[175]}$ Often, bacteria combine several of these approaches to protect themselves. Each antibiotic is rendered inactive by a variation of those general mechanisms. For example, penicillin targets cell wall biosynthesis whereas chloramphenicol and erythromycin inhibit protein synthesis. The outer membrane of some bacteria functions as a selective barrier

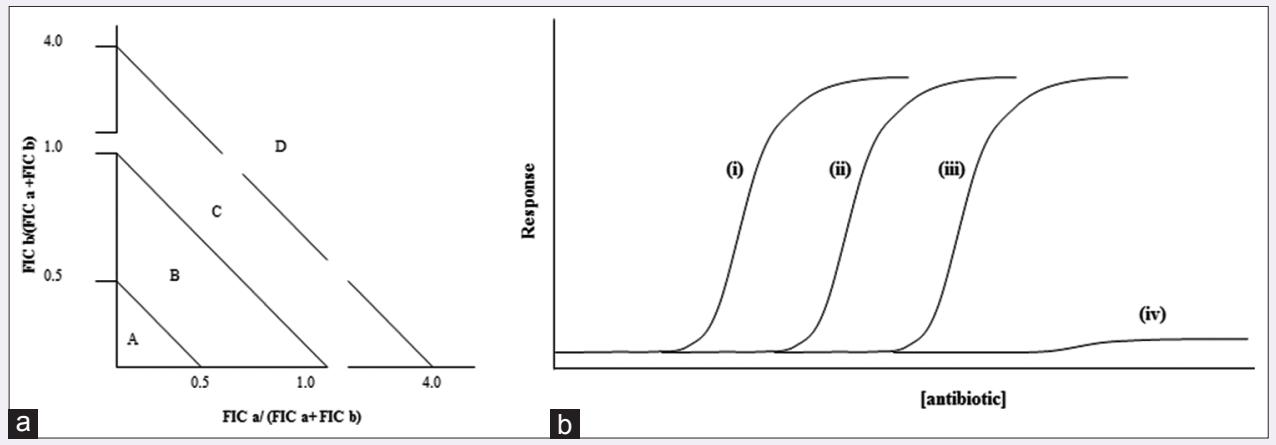

Figure 3: (a) An isobologram, used to determine whether drug combinations produce effects that differ from the effects of the drugs used individually. When the calculated ratio for two combined inhibitors fall in quadrants, A depicts synergy, B an additive effect, and C a non-interactive effect, whilst D depicts an antagonistic interaction (adapted from [164]). (b) Response of a candidate bacterial strain to a conventional antibiotic and/or a plant extract: (i) sensitive bacteria + antibiotic, or resistant bacteria + plant extract; (ii) resistant bacteria + antibiotic; (iii) extensively/totally resistant bacteria + antibiotic + plant extract; and (iv) extensively/totally resistant bacteria + antibiotic 
which contains integral outer membrane proteins, some of which provide entry and exit points for antibiotics. Loss or modification of these outer membrane proteins may lead to antimicrobial resistance due to reduced membrane permeability and thus, reduced uptake of antibiotics. ${ }^{[176]}$ A range of antibiotics including penicillin and chloramphenicol are particularly susceptible to these resistance mechanisms. Specific plant compounds have been reported to induce perturbations in the cell membrane and increase the permeability of antibiotics to bacterial cells. ${ }^{[176]}$ These membrane perturbations, coupled with the action of $\beta$-lactams on the transpeptidation of the cell membrane, may enhance the inhibitory activity of the antibiotic. ${ }^{[177]}$ Furthermore, some plant-derived compounds can improve the in vitro activity of peptidoglycan inhibiting antibiotics by directly attacking the same site in the cell wall.

\section{Recent studies into synergistic combinations of plant extract/compounds with conventional antibiotics}

Over the last decade, the number of studies examining the synergistic interaction between plant extracts and resistance-prone antibiotics has significantly increased. The endemic Sicilian plant Berberis aetnensis C. Presl. interacts synergistically with ciprofloxacin. ${ }^{[178]}$ Chloroform extracts derived from the leaves of $B$. aetnensis significantly lower the MIC of ciprofloxacin against $S$. aureus, Escherichia coli, and P. aeruginosa. A combination of antibiotics and extracts of clove, jambolan, pomegranate, and thyme demonstrated significant synergistic activity against a multi-resistant strain of $P$. aeruginosa. ${ }^{[179]}$ Similarly, enhanced antimicrobial activity was observed in combinations of clove-ampicillin and clove-tetracycline against K. pneumoniae and Proteus spp. respectively ${ }^{[179]}$ Furthermore, crude extracts of various other plants in combination with different antibiotics had significantly decreased MIC values against different strains of drug-resistant $P$. aeruginos ${ }^{[180]}$ and clinical isolates of MRSA. ${ }^{[181]}$ These synergistic studies not only show promise in the fight against drug-resistant pathogens but may also repurpose antibiotics that are generally ineffective alone.

Other recent studies have also reported interesting synergistic effects for other plant/antibiotic combinations. Isoflavones isolated from the plant Lupinus argenteus Pursh. potentiate the activity of the natural plant antibiotic berberine and the synthetic fluoroquinoline antibiotic norfloxacin. The isoflavone allows a greater concentration of berberine to accumulate in $S$. aureus cells by inhibiting the efflux mechanism (MDR pump). ${ }^{[172]}$ Similarly, Mezoneuron benthamianum Baill. and Securinega virosa (Roxb.) Baill. extracts act as efflux pump inhibitors (EPIs) for fluoroquinolone, tetracycline, and erythromycin in resistant strains of S. aureus (MRSA). ${ }^{[173]}$ As a consequence, M. benthamianum ethanol and chloroform extracts of $S$. virosa reduce the MIC of norfloxacin against $S$. aureus by a factor of $4 .{ }^{[173]}$ Berberis spp. are known for their production of the antimicrobial alkaloid berberine. ${ }^{[182]}$ However, they also produce an inhibitor of a $S$. aureus efflux pump, identified as 5-methoxyhydnocarpin (5-MHC). 5-MHC induces a significantly decreased MIC for berberine against $S$. aureus, greatly potentiating its efficacy. Similarly, Helichrysum longifolium DC. extracts have been reported to potentiate the activity of a broad range of antibiotics against multiple bacterial species. ${ }^{[177]}$ While the synergistic mechanism was not determined in that study, the authors suggested that the H. longifolium extracts contain broad spectrum antibiotic resistance modifying compounds.

Another study reported synergistic activity for Petalostigma spp. extracts in combination with multiple antibiotics. ${ }^{[183]}$ A methanolic Petalostigma spp. extract interacted synergistically with penicillin, chloramphenicol, and erythromycin to inhibit the growth of Proteus mirabilis. The P. mirabilis strain tested in that study was particularly resistant, being completely non-susceptible to chloramphenicol and erythromycin, and with only a low susceptibility to penicillin. All of these antibiotics are susceptible to resistance due to efflux pumps. ${ }^{[176,184]}$ A single efflux pump can provide bacteria with resistance to a wide array of chemically and structurally diverse antibiotics, and it is not uncommon for an organism to code for more than one efflux pump. It is therefore likely that compound(s) within that extract may block the efflux mechanism or alter the process of efflux and in so doing, extend the life of existing antibacterial drugs, allowing these antibiotics to again block the growth of the P. mirabilis strain. There are currently no EPI/antimicrobial drug combinations on the market. However, several recent studies have also reported EPI activity for several other plant extracts and compounds isolated from them. A recent study reported that carnosic acid isolated from Rosmarinus officinalis L. potentiated the activity of erythromycin. ${ }^{[176]}$ That study determined that the increased erythromycin activity was due to an inhibition of the bacterial MDR pumps by carsonic acid.

It is possible that the Petalostigma spp. extracts examined in the Ilanko et al. ${ }^{[183]}$ study may also contain an irreversible $\beta$-lactamase inhibitor which functions similarly to clavulanic acid to block the bacterial antimicrobial resistance mechanism. Alternatively (or in addition to MDR efflux pumps), the $P$. mirabilis strain used in that study may have acquired genes encoding for reduced-affinity penicillin-binding protein $2 \mathrm{a}$ (PBP2a), rendering $\beta$-lactam antibiotics ineffective. In another study, a bioactive fraction, F-10 was identified from Duabanga grandiflora. ${ }^{[185]}$ The F-10 fraction in this work was shown to act synergistically with ampicillin in inhibiting the growth of MRSA. Furthermore, investigations into the combinational mechanism revealed that there was a link to PBP2a inhibition. Western blot analysis was used to confirm that a combination of F-10 and ampicillin totally suppressed the expression of PBP2a in MRSA. It was postulated that F-10 interferes with the regulatory genes involved in the expression PBP2a. A phytochemical analysis revealed the presence of flavonoids and tannins in F10. Since PBPs are a group of protein enzymes, it appears likely that these phytochemicals may form nonspecific interactions and affect the bacterial cell biosynthesis.

Interestingly, the Ilanko et al. ${ }^{[183]}$ study also identified a lower polarity hexane Petalostigma spp. extract as blocking a different efflux pump mechanism in A. baylyi. The bacteria were completely resistant to tetracycline alone. Similarly, the extract alone was also ineffective against A. baylyi. However, a combination of the extract with tetracycline displayed potent growth inhibitory activity. Efflux pumps are the main bacterial resistance mechanism which renders tetracycline inactive ${ }^{[182]}$ A total of nine multidrug efflux systems have been identified in Acinetobacter spp. alone, including the potent tetracycline efflux protein Tet (A). ${ }^{[186]}$ It is therefore likely that the lower polarity extract compounds act to inhibit the A. baylyi tetracycline efflux pump. Similar studies with compounds isolated from a different plant species (Thymus vulgaris L.) identified the trihydroxyflavone baicalein as possessing a strong synergistic activity when used in conjunction with tetracycline against MRSA expressing Tet (K). ${ }^{[182,187]}$ Baicalein alone displays only weak antibacterial activity. Bioassay-guided isolation of plant extracts also identified several diterpenes (including carnosic acid) as potentiators of tetracycline activity against microbes possessing Tet (K) multidrug efflux mechanisms. ${ }^{[184,188]}$ Similarly, reserpine (a plant alkaloid) isolated from the Rauwolfia vomitoria Afzel. also demonstrated effective EPI activity against the bacterial MDR efflux pump which mediates tetracycline efflux in Bacillus subtilis. ${ }^{[184]}$

\section{CONCLUSIONS}

The early successes in antibiotic therapy yielded life-saving outcomes and is an example of possibly the most remarkable global scientific advance in modern medicine. The effectiveness of antibiotics used against a 
myriad of infectious microorganisms has been severely thwarted by the evolution of microbial resistance, arising as early as a decade following the discovery of penicillin. This worsening, ongoing trend has resulted in bacterial infections that are now completely resistant to all of the present day conventional medicines previously capable of eradicating the infection. Consequently, the use of synergistic treatment regimens incorporating plant extracts or purified compounds derived from plants has become an emerging area of great interest in the medical and scientific community. Not surprisingly, many such plants are those traditionally used by indigenous communities to treat infectious diseases. The evidence is accumulating that the use of plant extracts enhance the antibacterial activity of conventional antibiotics, serving to repurpose these compounds rather than replacing them.

There are numerous other advantages associated with the use of synergistic therapies. The plant-derived component would require a facile screening process to ensure that it is non-toxic, thus reducing the cost of development and testing while enhancing its speed to the market. This has already been demonstrated by the incorporation of the nonantibiotic $\beta$-lactamase inhibitors (e.g., clavulanic acid) alongside $\beta$-lactam drugs, which, in such cases, serve to protect the antibiotic from enzymatic destruction. Such a therapeutic strategy is quite specific, repurposing only a single class (or limited classes) of antibiotic. However, the development and use of efflux pump inhibitors may have a greater impact as it may repurpose a wider spectrum of antibiotics as efflux pumps often eject multiple antibiotics from the cell. Thus, this line of research may ultimately prove to be very useful.

While it remains imperative that research continues in the area of the development of new synthetic drugs and new scaffolds, the use of extracts derived from a myriad of traditionally used plant species as synergistic potentiators of medicines that had been previously effective signals a coming of age in the treatment of highly resistant infectious diseases that threaten the global community. By regaining the susceptibility of such pathogens to rigorously tested antibiotics, the fight against pervasive, transmissible, and deadly bacteria may finally shift in favor of the clinical treatment of such illnesses.

\section{Acknowledgments}

Financial support for this work was provided by the Environmental Futures Research Institute, the School of Natural Sciences, Griffith University, Australia and the Quality Use of Medicines Network, Australia.

\section{Financial support and sponsorship}

$\mathrm{Nil}$

\section{Conflicts of interest}

There are no conflicts of interest.

\section{REFERENCES}

1. Fleming $A$. On the antibacterial action of cultures of a penicillium, with special reference to their use in the isolation of $B$. influenzae. Br J Exp Pathol 1929;10:226.

2. Abraham EP, Chain E. An enzyme from bacteria able to destroy penicillin. Nature 1940;146:837

3. Rammelkamp CH, Maxon T. Resistance of Staphylococcus aureus to the action of penicillin. Exp Biol Med 1942;51:386-9

4. Davies J, Davies D. Origins and evolution of antibiotic resistance. Microbiol Mol Biol Rev 2010;74:417-33.

5. WHO. Antimicrobial Resistance. World Health Organization; 2016. Available from: http:// www.who.int/mediacentre/factsheets/fs194/en/. [Last cited on 2017 May 10].

6. Gill SR, Pop M, DeBoy RT, Eckburg PB, Turnbaugh PJ, Samuel BS, et al. Metagenomic analysis of the human distal gut microbiome. Science 2016;312:1355-9.
7. Magiorakos AP, Srinivasan A, Carey RB, Carmeli Y, Falagas ME, Giske CG, et al. Multidrug-resistant, extensively drug-resistant and pandrug-resistant bacteria: An international expert proposal for interim standard definitions for acquired resistance. Clin Microbiol Infect 2012;18:268-81.

8. Fleming A. Penicillin: Its practical application. Acad Med 1950;25:303.

9. Powers JH. Antimicrobial drug development - The past, the present, and the future. Clin Microbiol Infect 2004;10 Suppl 4:23-31.

10. Neu HC. The crisis in antibiotic resistance. Science 1992;257:1064-73.

11. Wellington EM, Boxall AB, Cross P, Feil EJ, Gaze WH, Hawkey PM, et al. The role of the natural environment in the emergence of antibiotic resistance in gram-negative bacteria. Lancet Infect Dis 2013;13:155-65.

12. Fischbach MA, Walsh CT. Antibiotics for emerging pathogens. Science 2009;325:1089-93

13. Spellberg B, Bartlett JG, Gilbert DN. The future of antibiotics and resistance. N Engl J Med 2013;368:299-302

14. Ventola CL. The antibiotic resistance crisis: Part 1: Causes and threats. PT 2015;40:277-83.

15. Levy SB. Antibiotic and antiseptic resistance: Impact on public health. Pediatr Infect Dis J 2000;19 10 Suppl: S120-2.

16. van Elsas JD, Bailey MJ. The ecology of transfer of mobile genetic elements. FEMS Microbiol Ecol 2002;42:187-97.

17. Holt KE, Wertheim H, Zadoks RN, Baker S, Whitehouse CA, Dance D, et al. Genomic analysis of diversity, population structure, virulence, and antimicrobial resistance in Klebsiella pneumoniae, an urgent threat to public health. Proc Natl Acad Sci U S A 2015;112:E3574-81.

18. Freire-Moran L, Aronsson B, Manz C, Gyssens IC, So AD, Monnet DL, et al. Critical shortage of new antibiotics in development against multidrug-resistant bacteria-Time to react is now. Drug Resist Updat 2011;14:118-24

19. Tanwar J, Das S, Fatima Z, Hameed S. Multidrug resistance: An emerging crisis. Interdiscip Perspect Infect Dis 2014;2014:541340.

20. Zilberberg MD, Shorr AF, Micek ST, Vazquez-Guillamet C, Kollef MH. Multi-drug resistance, inappropriate initial antibiotic therapy and mortality in Gram-negative severe sepsis and septic shock: A retrospective cohort study. Crit Care 2014;18:596.

21. Shah NS, Wright A, Bai GH, Barrera L, Boulahbal F, Martín-Casabona N, et al. Worldwide emergence of extensively drug-resistant tuberculosis. Emerg Infect Dis 2007;13:380-7.

22. Velayati AA, Masjedi MR, Farnia P, Tabarsi P, Ghanavi J, ZiaZarifi AH, et al. Emergence of new forms of totally drug-resistant tuberculosis bacilli: Super extensively drug-resistant tuberculosis or totally drug-resistant strains in Iran. Chest 2009;136:420-5.

23. Douthwaite AH, Trafford JA, McGill DA, Evans IE. Methicillin. Br Med J 1961;2:6.

24. Jevons MP, Coe AW, Parker MT. Methicillin resistance in staphylococci. Lancet 1963;1:904-7.

25. Wenzel RP. The emergence of methicillin-resistant Staphylococcus aureus. Ann Intern Med 1982;97:440-2.

26. Perencevich EN, Wong MT, Harris AD. National and regional assessment of the antibacterial soap market: A step toward determining the impact of prevalent antibacterial soaps. Am J Infect Control 2001;29:281-3.

27. Suller MT, Russell AD. Triclosan and antibiotic resistance in Staphylococcus aureus J Antimicrob Chemother 2000;46:11-8.

28. Giuliano CA, Rybak MJ. Efficacy of triclosan as an antimicrobial hand soap and its potential impact on antimicrobial resistance: A focused review. Pharmacotherapy 2015;35:328-36.

29. Levy SB. The challenge of antibiotic resistance. Sci Am 1998;278:46-53.

30. Morar M, Wright GD. The genomic enzymology of antibiotic resistance. Annu Rev Genet 2010;44:25-51.

31. Dever LA, Dermody TS. Mechanisms of bacterial resistance to antibiotics. Arch Intern Med 1991;151:886-95.

32. Tan JB, Lim YY. Critical analysis of current methods for assessing the in vitro antioxidant and antibacterial activity of plant extracts. Food Chem 2015;172:814-22.

33. Hawkey PM. Molecular epidemiology of clinically significant antibiotic resistance genes. $\mathrm{Br}$ J Pharmacol 2008;153 Suppl 1:S406-13.

34. Hartman BJ, Tomasz A. Low-affinity penicillin-binding protein associated with beta-lactam resistance in Staphylococcus aureus. J Bacteriol 1984;158:513-6.

35. Aust MO, Godlinski F, Travis GR, Hao X, McAllister TA, Leinweber P, et al. Distribution of sulfamethazine, chlortetracycline and tylosin in manure and soil of Canadian feedlots after subtherapeutic use in cattle. Environ Pollut 2008;156:1243-51.

36. Cromwell GL. Why and how antibiotics are used in swine production. Anim Biotechnol 2002;13:7-27. 
37. Singer RS, Hofacre CL. Potential impacts of antibiotic use in poultry production. Avian Dis 2006;50:161-72.

38. Cabello FC. Heavy use of prophylactic antibiotics in aquaculture: A growing problem for human and animal health and for the environment. Environ Microbiol 2006;8:1137-44.

39. Massé DI, Saady NM, Gilbert Y. Potential of biological processes to eliminate antibiotics in livestock manure: An overview. Animals (Basel) 2014;4:146-63.

40. Rhouma M, Beaudry F, Letellier A. Resistance to colistin: What is the fate for this antibiotic in pig production? Int J Antimicrob Agents 2016;48:119-26.

41. Wichmann F, Udikovic-Kolic N, Andrew S, Handelsman J. Diverse antibiotic resistance genes in dairy cow manure. MBio 2014;5:e01017.

42. Zhu YG, Johnson TA, Su JQ, Qiao M, Guo GX, Stedtfeld RD, et al. Diverse and abundant antibiotic resistance genes in Chinese swine farms. Proc Natl Acad Sci 2013;110:3435-40.

43. Rasamiravaka T, Andriatsitohanana TT, Rasamindrakotroka A. Evaluation of methicillin-resistant Staphylococcus aureus nasal carriage in Malagasy pig and poultry non-industrial farmers. J Infect Dev Ctries 2017;11:129-35.

44. Shah SQ, Cabello FC, L'abée-Lund TM, Tomova A, Godfrey HP, Buschmann AH, et al. Antimicrobial resistance and antimicrobial resistance genes in marine bacteria from salmon aquaculture and non-aquaculture sites. Environ Microbiol 2014;16:1310-20.

45. Kinney CA, Furlong ET, Zaugg SD, Burkhard MR, Werner SL, Cahill JD, et al. Survey of organic wastewater contaminants in biosolids destined for land application. Environ Sci Technol 2006;40:7207-15.

46. Hu X, Zhou Q, Luo Y. Occurrence and source analysis of typical veterinary antibiotics in manure, soil, vegetables and groundwater from organic vegetable bases, northern China. Environ Pollut 2010;158:2992-8.

47. Tijani JO, Fatoba OO, Petrik LF. A review of pharmaceuticals and endocrine-disrupting compounds: Sources, effects, removal, and detections. Water Air Soil Pollut 2013;224:1770.

48. McKenna M. CDC Threat Report: We Will Soon be in a Post-Antibiotic Era. Wired; 2013. Available from: https://www.wired.com/2013/09/cdc-amr-rpt1/. [Last cited on 2017 Feb 16].

49. Blumberg HM, Burman WJ, Chaisson RE, Daley CL, Etkind SC, Friedman LN, et al. American Thoracic Society/Centers for Disease Control and Prevention/Infectious Diseases Society of America: Treatment of tuberculosis. Am J Respir Crit Care Med 2003;167:603-62.

50. Engberg J, Aarestrup FM, Taylor DE, Gerner-Smidt P, Nachamkin I. Quinolone and macrolide resistance in Campylobacter jejuni and E. coli: Resistance mechanisms and trends in human isolates. Emerg Infect Dis 2001;7:24.

51. Gerding DN. Clindamycin, cephalosporins, fluoroquinolones, and Clostridium difficile-associated diarrhea: This is an antimicrobial resistance problem. Clin Infect Dis 2004;38:646-8.

52. Arias CA, Murray BE. The rise of the Enterococcus: Beyond vancomycin resistance. Nat Rev Microbiol 2012;10:266-78.

53. Pennington H. Escherichia coli O157. Lancet 2010;376:1428-35.

54. Mégraud F. H pylori antibiotic resistance: Prevalence, importance, and advances in testing. Gut 2004;53:1374-84

55. Thung I, Aramin H, Vavinskaya V, Gupta S, Park JY, Crowe SE, et al. Review article: The global emergence of Helicobacter pylori antibiotic resistance. Aliment Pharmacol Ther 2016;43:514-33

56. Ah YM, Kim AJ, Lee JY. Colistin resistance in Klebsiella pneumoniae. Int J Antimicrob Agents 2014;44:8-15.

57. Miotto P, Cabibbe AM, Feuerriegel S, Casali N, Drobniewski F, Rodionova $Y$, et al. Mycobacterium tuberculosis pyrazinamide resistance determinants: A multicenter study. MBio 2014;5:e01819-14.

58. Nebenzahl-Guimaraes H, Jacobson KR, Farhat MR, Murray MB. Systematic review of allelic exchange experiments aimed at identifying mutations that confer drug resistance in Mycobacterium tuberculosis. J Antimicrob Chemother 2013;69:331-42:dkt358.

59. Kirkcaldy RD, Bolan GA, Wasserheit JN. Cephalosporin-resistant gonorrhea in North America. JAMA 2013;309:185-7.

60. Korytny A, Riesenberg K, Saidel-Odes L, Schlaeffer F, Borer A. Bloodstream infections caused by multi-drug resistant Proteus mirabilis: Epidemiology, risk factors and impact of multi-drug resistance. Infect Dis (Lond) 2016;48:428-31.

61. ECDC, EMEA. European Centre for Disease Prevention and Control (ECDC) \& European Medicines Agency (EMEA). Joint Technological Report: The Bacterial Challenge. Time to React. ECDC-EMEA, Stockholm; 2009.

62. Cohen ML. Epidemiology of drug resistance: Implications for a post-antimicrobial era. Science 1992;257:1050-5.
63. Hawkey PM, Jones AM. The changing epidemiology of resistance. J Antimicrob Chemother 2009;64 Suppl 1:i3-10.

64. Gould IM. The epidemiology of antibiotic resistance. Int J Antimicrob Agents 2008;32 Suppl 1:S2-9.

65. Centers for Disease Control and Prevention (CDC). Plan to combat extensively drug-resistant tuberculosis: Recommendations of the Federal Tuberculosis Task Force. MMWR Recomm Rep 2009;58:1-43

66. Cha AE. Five Big Wins: Congress Boosts Medical Science Funding in Key Areas. The Washington Post; 2017. Available from: https://www.washingtonpost.com/news/to-yourhealth/wp/2017/05/01/five-big-wins-congress-boosts-medical-science-funding-in-key-areas. [Last cited on 2017 May 10]

67. Bush K, Courvalin P, Dantas G, Davies J, Eisenstein B, Huovinen P, et al. Tackling antibiotic resistance. Nat Rev Microbiol 2011;9:894-6.

68. Spadafino JT, Cohen B, Liu J, Larson E. Temporal trends and risk factors for extended-spectrum beta-lactamase-producing Escherichia coli in adults with catheter-associated urinary tract infections. Antimicrob Resist Infect Control 2014;3:39.

69. Uttley $\mathrm{AH}$, Collins $\mathrm{CH}$, Naidoo J, George RC. Vancomycin-resistant enterococci. Lancet 1988;1:57-8.

70. Leclercq R, Derlot E, Duval J, Courvalin P. Plasmid-mediated resistance to vancomycin and teicoplanin in Enterococcus faecium. N Engl J Med 1988;319:157-61.

71. Cetinkaya Y, Falk P, Mayhall CG. Vancomycin-resistant enterococci. Clin Microbiol Rev 2000;13:686-707.

72. Earnest J. Fact Sheet: Obama Administration Releases National Action Plan to Combat Antibiotic-Resistant Bacteria; 2015. Available from: https://www.whitehouse.gov/the-pressoffice/2015/03/27/fact-sheet-obama-administration-releases-national-action-plan-combat-ant. [Last cited on 2016 Dec 10].

73. Gonzales RD, Schreckenberger PC, Graham MB, Kelkar S, DenBesten K, Quinn JP. Infections due to vancomycin-resistant Enterococcus faecium resistant to linezolid. Lancet 2001;357:1179.

74. Pogue JM, Paterson DL, Pasculle AW, Potoski BA. Determination of risk factors associated with isolation of linezolid-resistant strains of vancomycin-resistant Enterococcus. Infect Control Hosp Epidemiol 2007;28:1382-8.

75. do Prado GV, Marchi AP, Moreno LZ, Rizek C, Amigo U, Moreno AM, et al. Virulence and resistance pattern of a novel sequence type of linezolid-resistant Enterococcus faecium identified by whole-genome sequencing. J Glob Antimicrob Resist 2016;6:27-31.

76. Lim D, Strynadka NC. Structural basis for the beta lactam resistance of PBP2a from methicillin-resistant Staphylococcus aureus. Nat Struct Biol 2002;9:870-6.

77. Subramanian A, Chitalia V, Vaidya SP, Warke RV, Chowdhary A, Deshmukh RA. Detection of macrolide, lincosamide and streptogramin resistance among methicillin resistant Staphylococcus aureus (MRSA) in Mumbai. JKIMSU 2015;4:10-16.

78. Milheiriço $C$, de Lencastre $H$, Tomasz A. Full-genome sequencing identifies in the genetic background several determinants that modulate the resistance phenotype in methicillin-resistant Staphylococcus aureus strains carrying the novel mecC gene. Antimicrob Agents Chemother. 2017;61. pii: e02500-16.

79. Moran GJ, Krishnadasan A, Gorwitz RJ, Fosheim GE, McDougal LK, Carey RB, et al. Methicillin-resistant $S$. aureus infections among patients in the emergency department. N Engl J Med. 2006;355:666-74.

80. Bouchiat C, Curtis S, Spiliopoulou I, Bes M, Cocuzza C, Codita I, et al. MRSA infections among patients in the emergency department: A European multicentre study. J Antimicrob Chemother 2016;7:372-5:dkw431.

81. Bassetti M, Peghin M, Trecarichi EM, Carnelutti A, Righi E, Del Giacomo P, et al. Characteristics of Staphylococcus aureus bacteraemia and predictors of early and late mortality. PLoS One 2017;12:e0170236.

82. Dalovisio JR. IDSA: Infancy to adulthood in four decades. Clin Infect Dis. 2005;40:574-8.

83. Fridkin SK, Hageman J, McDougal LK, Mohammed J, Jarvis WR, Perl TM, et al. Epidemiological and microbiological characterization of infections caused by Staphylococcus aureus with reduced susceptibility to vancomycin, United States, 1997-2001. Clin Infect Dis 2003;36:429-39

84. Sabouni F, Movahedi Z, Mahmoudi S, Pourakbari B, Keshavarz Valian S, Mamishi S. High frequency of vancomycin resistant Enterococcus faecalis in children: An alarming concern. J Prev Med Hyg 2016;57:E201-4.

85. Keynan Y, Rubinstein E. The changing face of Klebsiella pneumoniae infections in the community. Int J Antimicrob Agents 2007;30:385-9. 
86. Winnett V, Sirdaarta J, White A, Clarke FM, Cock IE. Inhibition of Klebsiella pneumoniae growth by selected Australian plants: Natural approaches for the prevention and management of ankylosing spondylitis. Inflammopharmacology 2017;25:223-35.

87. Papanicolaou GA, Medeiros AA, Jacoby GA. Novel plasmid-mediated beta-lactamase (MIR-1) conferring resistance to oxyimino- and alpha-methoxy beta-lactams in clinical isolates of Klebsiella pneumoniae. Antimicrob Agents Chemother 1990;34:2200-9.

88. Bradford PA, Urban C, Mariano N, Projan SJ, Rahal JJ, Bush K. Imipenem resistance in Klebsiella pneumoniae is associated with the combination of ACT-1, a plasmid-mediated AmpC beta-lactamase, and the foss of an outer membrane protein. Antimicrob Agents Chemother 1997;41:563-9.

89. Coudron PE, Moland ES, Thomson KS. Occurrence and detection of AmpC beta-lactamases among Escherichia coli, Klebsiella pneumoniae, and Proteus mirabilis isolates at a veterans medical center. J Clin Microbiol 2000;38:1791-6.

90. Yigit H, Queenan AM, Anderson GJ, Domenech-Sanchez A, Biddle JW, Steward CD, et al. Novel carbapenem-hydrolyzing $\beta$-lactamase, KPC-1, from a carbapenem-resistant strain of Klebsiella pneumoniae. Antimicrob Agents Chemother 2001;45:1151-61.

91. Smith Moland E, Hanson ND, Herrera VL, Black JA, Lockhart TJ, Hossain A, et al. Plasmid-mediated, carbapenem-hydrolysing $\beta$-lactamase, KPC-2, in Klebsiella pneumoniae isolates. J Antimicrob Chemother 2003;51:711-4.

92. Woodford N, Tierno PM Jr., Young K, Tysall L, Palepou MF, Ward E, et al. Outbreak of Klebsiella pneumoniae producing a new carbapenem-hydrolyzing class A $\beta$-lactamase, KPC-3, in a New York Medical Center. Antimicrob Agents Chemother 2004;48:4793-9.

93. Bleumin D, Cohen MJ, Moranne O, Esnault VL, Benenson S, Paltiel O, et al. Carbapenem-resistant Klebsiella pneumoniae is associated with poor outcome in hemodialysis patients. J Infect 2012;65:318-25.

94. Kalpoe JS, Sonnenberg E, Factor SH, del Rio Martin J, Schiano T, Patel G, et al. Mortality associated with carbapenem-resistant Klebsiella pneumoniae infections in liver transplant recipients. Liver Transpl 2012;18:468-74.

95. Zhang Y, Zeng J, Liu W, Zhao F, Hu Z, Zhao C, et al. Emergence of a hypervirulent carbapenem-resistant Klebsiella pneumoniae isolate from clinical infections in China. J Infect 2015;71:553-60.

96. Du J, Cao J, Shen L, Bi W, Zhang X, Liu H, et al. Molecular epidemiology of extensively drug-resistant Klebsiella pneumoniae outbreak in Wenzhou, Southern China. J Med Microbiol 2016;65:1111-8.

97. Liu YY, Wang Y, Walsh TR, Yi LX, Zhang R, Spencer J, et al. Emergence of plasmid-mediated colistin resistance mechanism MCR-1 in animals and human beings in China: A microbiological and molecular biological study. Lancet Infect Dis 2016;16:161-8.

98. Spellberg B, Powers JH, Brass EP, Miller LG, Edwards JE Jr. Trends in antimicrobial drug development: Implications for the future. Clin Infect Dis 2004;38:1279-86.

99. Sciarretta K, Røttingen JA, Opalska A, Van Hengel AJ, Larsen J. Economic incentives for antibacterial drug development: Literature review and considerations from the transatlantic task force on antimicrobial resistance. Clin Infect Dis 2016;63:1470-4.

100. Spellberg B, Guidos R, Gilbert D, Bradley J, Boucher HW, Scheld WM, et al. Infectious Diseases Society of America. The epidemic of antibiotic-resistant infections: A call to action for the medical community from the Infectious Diseases Society of America. Clin Infect Dis 2008;46:155-64.

101. Arrowsmith J. Trial watch: Phase III and submission failures: 2007-2010. Nat Rev Drug Discov 2011;10:87.

102. The PEW Charitable Trusts. Antibiotics Currently in Clinical Development; 2016. Available from: http://www.pewtrusts.org/ /media/assets/2016/05/antibiotics-currently-in-clinical-dev elopment.pdf. [Last cited on 2017 Jan 20].

103. Pfaller MA, Sader HS, Rhomberg PR, Flamm RK. In vitro activity of delafloxacin against contemporary bacterial pathogens from the United States and Europe, 2014. Antimicrob Agents Chemother 2017;61. pii: E02609-16.

104. Kim T, Park SJ, Chong YP, Park KH, Lee YM, Hong HL, et al. Fluoroquinolone resistance of Streptococcus pneumoniae isolates causing invasive disease: Special focus on zabofloxacin. Diagn Microbiol Infect Dis 2016;86:181-3.

105. Ito A, Nishikawa T, Matsumoto S, Yoshizawa H, Sato T, Nakamura R, et al. Siderophore cephalosporin cefiderocol utilizes ferric iron transporter systems for antibacterial activity against Pseudomonas aeruginosa. Antimicrob Agents Chemother 2016;60:7396-401.

106. Pfaller MA, Huband MD, Rhomberg PR, Flamm RK. Surveillance of omadacycline activity against clinical isolates from a global collection (North America, Europe, Latin America, Asia-Western Pacific), 2010-2011. Antimicrob Agents Chemother 2017;61. pii: e00018-17

107. Solomkin J, Evans D, Slepavicius A, Lee P, Marsh A, Tsai L, et al. Assessing the efficacy and safety of eravacycline vs. ertapenem in complicated intra-abdominal infections in the investigating gram-negative infections treated with eravacycline (IGNITE 1) trial: A Randomized Clinical Trial. JAMA Surg 2017;152:224-32.

108. Eyal Z, Matzov D, Krupkin M, Paukner S, Riedl R, Rozenberg H, et al. A novel pleuromutilin antibacterial compound, its binding mode and selectivity mechanism. Sci Rep 2016;6:39004.

109. Lucasti C, Vasile L, Sandesc D, Venskutonis D, McLeroth P, Lala M, et al. Phase 2, dose-ranging study of relebactam with imipenem-cilastatin in subjects with complicated intra-abdominal infection. Antimicrob Agents Chemother 2016;60:6234-43.

110. Liapikou A, Torres A. Emerging drugs for nosocomial pneumonia. Expert Opin Emerg Drugs 2016;21:331-41.

111. Bassères E, Endres BT, Dotson KM, Alam MJ, Garey KW. Novel antibiotics in development to treat Clostridium difficile infection. Curr Opin Gastroenterol 2017;33:1-7.

112. ClinicalTrials.gov. Oral Sodium Fusidate (CEM-102) Versus Oral Linezolid for the Treatment of Acute Bacterial Skin and Skin Structure Infections; 2017. Available from: https://www. clinicaltrials.gov/ct2/show/NCT02570490. [Last cited on 2017 Feb 25].

113. Castanheira M, Rhomberg PR, Flamm RK, Jones RN. Effect of the ß-lactamase inhibitor vaborbactam combined with meropenem against serine carbapenemase-producing Enterobacteriaceae. Antimicrob Agents Chemother 2016;60:5454-8.

114. del Carmen López-Diaz M, Culebras E, Rodríguez-Avial I, Rios E, Viñuela-Prieto JM, Picazo JJ, et al. Plazomicin activity against 346 extended-spectrum- $\beta$-lactamase/AmpC-producing Escherichia coli urinary isolates, related to aminoglycoside-modifying enzymes characterized. Antimicrob Agents Chemother 2017;61:e02454-16

115. Zhanel GG, Hartel E, Adam H, Zelenitsky S, Zhanel MA, Golden A, et al. Solithromycin A novel fluoroketolide for the treatment of community-acquired bacterial pneumonia. Drugs 2016;76:1737-57.

116. Zhanel GG, Chung P, Adam H, Zelenitsky S, Denisuik A, Schweizer F, et al. Ceftolozane/ tazobactam: A novel cephalosporin/ß-lactamase inhibitor combination with activity against multidrug-resistant gram-negative bacilli. Drugs 2014;74:31-51.

117. Lucasti C, Popescu I, Ramesh MK, Lipka J, Sable C. Comparative study of the efficacy and safety of ceftazidime/avibactam plus metronidazole versus meropenem in the treatment of complicated intra-abdominal infections in hospitalized adults: Results of a randomized, double-blind, Phase II trial. J Antimicrob Chemother 2013;68:1183-92.

118. Humphries RM, Yang S, Hemarajata P, Ward KW, Hindler JA, Miller SA, et al. First report of ceftazidime-avibactam resistance in a KPC-3-expressing Klebsiella pneumoniae isolate. Antimicrob Agents Chemother. 2015;59:6605-7.

119. Mishra RP, Oviedo-Orta E, Prachi P, Rappuoli R, Bagnoli F. Vaccines and antibiotic resistance. Curr Opin Microbiol 2012;15:596-602

120. Stephens DS, Zughaier SM, Whitney CG, Baughman WS, Barker L, Gay K, et al. Incidence of macrolide resistance in Streptococcus pneumoniae after introduction of the pneumococcal conjugate vaccine: Population-based assessment. Lancet. 2005;365:855-63.

121. Rashid H, Khandaker G, Booy R. Vaccination and herd immunity: What more do we know? Curr Opin Infect Dis 2012;25:243-9

122. Lynch JP $3^{\text {rd }}$, Zhanel GG. Streptococcus pneumoniae: Epidemiology and risk factors, evolution of antimicrobial resistance, and impact of vaccines. Curr Opin Pulm Med 2010;16:217-25.

123. Lyu S, Yao KH, Dong F, Xu BP, Liu G, Wang Q, et al. Vaccine serotypes of Streptococcus pneumoniae with high-level antibiotic resistance isolated more frequently seven years after the licensure of PCV7 in Beijing. Pediatr Infect Dis J 2016;35:316-21.

124. D'Herelle F. On an invisible microbe antagonistic toward dysenteric bacilli: Brief note by Mr. F. D’Herelle, presented by Mr. Roux 1917. Res Microbiol 2007;158:553-4.

125. Kochetkova VA, Mamontov AS, Moskovtseva RL, Erastova El, Trofimov El, Popov MI, et al Phagotherapy of postoperative suppurative-inflammatory complications in patients with neoplasms. Sov Med 1989;6:23-6.

126. Bogovazova GG, Voroshilova NN, Bondarenko VM, Gorbatkova GA, Afanas'eva EV, Kazakova TB, et al. Immunobiological properties and therapeutic effectiveness of preparations from Klebsiella bacteriophages. Zh Mikrobiol Epidemiol Immunobiol 1992;3:30-3.

127. Miedzybrodzki R, Fortuna W, Weber-Dabrowska B, Górski A. Phage therapy of staphylococca infections (including MRSA) may be less expensive than antibiotic treatment. Postepy Hig Med Dosw (Online) 2007;61:461-5

128. Hraiech S, Brégeon F, Rolain JM. Bacteriophage-based therapy in cystic fibrosis-associated Pseudomonas aeruginosa infections: Rationale and current status. Drug Des Devel Ther 2015:9:3653-63

129. Duraipandiyan $\mathrm{V}$, Ayyanar M, Ignacimuthu S. Antimicrobial activity of some ethnomedicinal plants used by Paliyar tribe from Tamil Nadu, India. BMC Complement Altern Med 2006;6:35. 
130. Yadav RN, Agarwala M. Phytochemical analysis of some medicinal plants. J Phytol 2011;3:12.

131. Srinivasan D, Nathan S, Suresh T, Lakshmana Perumalsamy P. Antimicrobial activity of certain Indian medicinal plants used in folkloric medicine. J Ethnopharmacol 2001;74:217-20.

132. Lewis K, Ausubel FM. Prospects for plant-derived antibacterials. Nat Biotechnol 2006;24:1504-7.

133. Srivastava J, Chandra H, Nautiyal AR, Kalra SJ. Antimicrobial resistance (AMR) and 5 plant-derived antimicrobials (PDAms) as an alternative drug line to control infections. 3 Biotech 2014;4:451-60.

134. Pierard-Franchimont C, Goffin V, Decroix J, Piérard GE. A multicenter randomized trial of ketoconazole $2 \%$ and zinc pyrithione $1 \%$ shampoos in severe dandruff and seborrheic dermatitis. Skin Pharmacol Physiol 2002;15:434-41.

135. Cleveland KO. Antimicrobial agents: Antibacterials and antifungals. Clinical Infectious Diseases 2006;42:1816. Bryskier A, editor. Washington, DC: ASM Press; 2005.

136. Smyth T, Ramach VN, Brooks P, Smyth WF. A study of the antibacterial activities of selected Australian medicinal plants. J Pharmacognosy Phytother 2009;1:82-6.

137. Su X, Howell AB, D'Souza DH. Antibacterial effects of plant-derived extracts on methicillin-resistant Staphylococcus aureus. Foodborne Pathog Dis 2012;9:573-8.

138. Ahmad I, Mehmood Z, Mohammad F. Screening of some Indian medicinal plants for their antimicrobial properties. J Ethnopharmacol 1998;62:183-93.

139. Ahmad I, Beg AZ. Antimicrobial and phytochemical studies on 45 Indian medicinal plants against multi-drug resistant human pathogens. J Ethnopharmacol 2001;74:113-23.

140. Li Y, Xu C, Zhang Q, Liu JY, Tan R $\times$. In vitro anti-Helicobacter pylori action of 30 Chinese herbal medicines used to treat ulcer diseases. J Ethnopharmacol 2005;98:329-33.

141. Hoffmann JJ, Timmermann BN, McLaughlin SP, Punnapayak H. Potential antimicrobial activity of plants from the Southwestern United States. IJP 1993;31:101-15.

142. Hübsch Z, Van Zyl RL, Cock IE, Van Vuuren SF. Interactive antimicrobial and toxicity profiles of conventional antimicrobials with Southern African medicinal plants. S Afr J Bot 2014;93:185-97.

143. Kelmanson JE, Jäger $A K$, van Staden J. Zulu medicinal plants with antibacterial activity. J Ethnopharmacol 2000;69:241-6.

144. Palombo EA, Semple SJ. Antibacterial activity of traditional Australian medicinal plants. J Ethnopharmacol 2001;77:151-7.

145. Palombo EA, Semple SJ. Antibacterial activity of Australian plant extracts against methicillin-resistant Staphylococcus aureus (MRSA) and vancomycin-resistant enterococci (VRE). J Basic Microbiol 2002;42:444-8.

146. Vesoul J, Cock IE. An examination of the medicinal potential of Pittosporum phylliraeoides: Toxicity, antibacterial and antifungal activities. Pharmacogn Commun 2011;1:8-17.

147. Cock IE, Winnett V, Sirdaarta J, Matthews B. The potential of selected Australian medicinal plants with anti-Proteus activity for the treatment and prevention of rheumatoid arthritis. Pharmacogn Mag 2015;11 Suppl 1:S190-208.

148. Chariandy CM, Seaforth CE, Phelps RH, Pollard GV, Khambay BP. Screening of medicinal plants from Trinidad and Tobago for antimicrobial and insecticidal properties. J Ethnopharmacol 1999;64:265-70.

149. Efferth T. From ancient herb to versatile, modern drug: Artemisia annua and artemisinin for cancer therapy. In: Seminars in Cancer Biology. Cambridge, USA: Academic Press; 2017.

150. Burns J, Yokota T, Ashihara H, Lean ME, Crozier A. Plant foods and herbal sources of resveratrol. J Agric Food Chem 2002;50:3337-40.

151. Paulo L, Ferreira S, Gallardo E, Queiroz JA, Domingues F. Antimicrobial activity and effects of resveratrol on human pathogenic bacteria. World J Microbiol Biotechnol 2010;26:1533-8.

152. Taylor EJ, Yu Y, Champer J, Kim J. Resveratrol demonstrates antimicrobial effects against Propionibacterium acnes in vitro. Dermatol Ther (Heidelb) 2014;4:249-57.

153. Imanshahidi M, Hosseinzadeh $\mathrm{H}$. Pharmacological and therapeutic effects of Berberis vulgaris and its active constituent, berberine. Phytother Res 2008;22:999-1012.

154. Tillhon M, Guamán Ortiz LM, Lombardi P, Scovassi Al. Berberine: New perspectives for old remedies. Biochem Pharmacol 2012;84:1260-7.

155. Inui T, Wang Y, Deng S, Smith DC, Franzblau SG, Pauli GF. Counter-current chromatography based analysis of synergy in an anti-tuberculosis ethnobotanical. J Chromatogr A 2007; $1151: 211-5$

156. Sakagami $Y$, linuma M, Piyasena KG, Dharmaratne HR. Antibacterial activity of $\alpha$-mangostin against vancomycin resistant Enterococci (VRE) and synergism with antibiotics. Phytomedicine 2005;12:203-8.

157. Phitaktim S, Chomnawang M, Sirichaiwetchakoon K, Dunkhunthod B, Hobbs G, Eumkeb G. Synergism and the mechanism of action of the combination of $\alpha$-mangostin isolated from Garcinia mangostana L. and oxacillin against an oxacillin-resistant Staphylococcus saprophyticus. BMC Microbiol 2016;16:195.

158. Siriwong S, Teethaisong Y, Thumanu K, Dunkhunthod B, Eumkeb G. The synergy and mode of action of quercetin plus amoxicillin against amoxicillin-resistant Staphylococcus epidermidis. BMC Pharmacol Toxicol 2016;17:39.

159. Morita Y, Nakashima K, Nishino K, Kotani K, Tomida J, Inoue M, et al. Berberine is a novel type efflux inhibitor which attenuates the MexXY-mediated aminoglycoside resistance in Pseudomonas aeruginosa. Front Microbiol 2016;7:1223.

160. Zuo GY, Li Y, Wang T, Han J, Wang GC, Zhang YL, et al. Synergistic antibacterial and antibiotic effects of bisbenzylisoquinoline alkaloids on clinical isolates of methicillin-resistant Staphylococcus aureus (MRSA) Molecules 2011;16:9819-26.

161. Zuo GY, Li Y, Han J, Wang GC, Zhang YL, Bian ZQ. Antibacterial and synergy of berberines with antibacterial agents against clinical multi-drug resistant isolates of methicillin-resistant Staphylococcus aureus (MRSA). Molecules 2012;17:10322-30.

162. Fadli M, Saad A, Sayadi S, Chevalier J, Mezrioui NE, Pagès JM, et al. Antibacterial activity of Thymus maroccanus and Thymus broussonetii essential oils against nosocomial infection-bacteria and their synergistic potential with antibiotics. Phytomedicine 2012;19:464-71.

163. Mahboubi M, Bidgoli FG. Antistaphylococcal activity of Zataria multiflora essential oil and its synergy with vancomycin. Phytomedicine 2010;17:548-50.

164. van Vuuren S, Viljoen A. Plant-based antimicrobial studies - Methods and approaches to study the interaction between natural products. Planta Med 2011;77:1168-82.

165. WHO. Global Tuberculosis Report 2016. World Health Organization; 2016. Available from: http://www.who.int/tb/publications/global_report/en/. [Last cited on 2017 Feb 10].

166. Chovanová R, Mikulášová $M$, Vaverková $S$. In vitro antibacterial and antibiotic resistance modifying effect of bioactive plant extracts on methicillin-resistant Staphylococcus epidermidis. Int J Microbiol 2013;2013:760969.

167. Levinson W, Jawetz E. Medical Microbiology and Immunology: Examination and Board Review. NY, USA: Lange Medical Books/McGraw-Hill; 2002.

168. Hall MJ, Middleton RF, Westmacott D. The fractional inhibitory concentration (FIC) index as a measure of synergy. J Antimicrob Chemother 1983;11:427-33.

169. Tallarida RJ. An overview of drug combination analysis with isobolograms. J Pharmacol Exp Ther 2006;319:1-7.

170. Neu HC, Fu KP. Clavulanic acid, a novel inhibitor of $\beta$-lactamases. Antimicrob Agents Chemother 1978;14:650-5.

171. Abate G, Miörner H. Susceptibility of multidrug-resistant strains of Mycobacterium tuberculosis to amoxycillin in combination with clavulanic acid and ethambutol. J Antimicrob Chemother 1998;42:735-40.

172. Morel C, Stermitz FR, Tegos G, Lewis K. Isoflavones as potentiators of antibacterial activity J Agric Food Chem 2003;51:5677-9.

173. Dickson RA, Houghton PJ, Hylands PJ, Gibbons S. Antimicrobial, resistance-modifying effects, antioxidant and free radical scavenging activities of Mezoneuron benthamianum Baill. Securinega virosa Roxb. and WIId. and Microglossa pyrifolia Lam. Phytother Res 2006;20:41-5.

174. Chusri S, Villanueva I, Voravuthikunchai SP, Davies J. Enhancing antibiotic activity: A strategy to control Acinetobacter infections. J Antimicrob Chemother 2009;64:1203-11.

175. Leclercq R. Mechanisms of resistance to macrolides and lincosamides: Nature of the resistance elements and their clinical implications. Clin Infect Dis 2002;34:482-92.

176. Abreu AC, McBain AJ, Simões M. Plants as sources of new antimicrobials and resistance-modifying agents. Nat Prod Rep 2012;29:1007-21.

177. Aiyegoro OA, Afolayan AJ, Okoh Al. In vitro antibacterial activities of crude extracts of the leaves of Helichrysum longifolium in combination with selected antibiotics. Afr J Pharm Pharmacol 2009;3:293-300.

178. Musumeci R, Speciale A, Costanzo R, Annino A, Ragusa S, Rapisarda A, et al. Berberis aetnensis C. Presl. extracts: Antimicrobial properties and interaction with ciprofloxacin. Int $\mathrm{J}$ Antimicrob Agents 2003;22:48-53.

179. Nascimento GG, Locatelli J, Freitas PC, Silva GL. Antibacterial activity of plant extracts and phytochemicals on antibiotic-resistant bacteria. Braz J Microbiol 2000;31:247-56.

180. Adwan G, Abu-Shanab B, Adwan K. Antibacterial activities of some plant extracts alone and in combination with different antimicrobials against multidrug-resistant Pseudomonas aeruginosa strains. Asian Pac JTrop Med 2010;3:266-69.

181. Adwan GM, Abu-Shanab BA, Adwan KM. In vitro activity of certain drugs in combination with plant extracts against Staphylococcus aureus infections. Afr J Biotechnol 2009;8:4239.

182. Mikulášová M, Chovanová R, Vaverková Š. Synergism between antibiotics and plant extracts 
or essential oils with efflux pump inhibitory activity in coping with multidrug-resistant staphylococci. Phytochem Rev 2016;15:651-62.

183. Ilanko A, White A, Cock IE. The interactive antimicrobial activity of conventional antibiotics and Petalostigma spp. extracts against bacterial triggers of some autoimmune inflammatory diseases. BMC Complement Altern Med 2017; [In press].

184. Stavri M, Piddock LJ, Gibbons S. Bacterial efflux pump inhibitors from natural sources. J Antimicrob Chemother 2007;59:1247-60

185. Santiago C, Pang EL, Lim KH, Loh HS, Ting KN. Inhibition of penicillin-binding protein 2a (PBP2a) in methicillin resistant Staphylococcus aureus (MRSA) by combination of ampicillin and a bioactive fraction from Duabanga grandiflora. BMC Complement Altern Med 2015;15:178.

186. Brzoska AJ, Hassan KA, de Leon EJ, Paulsen IT, Lewis PJ. Single-step selection of drug resistant Acinetobacter baylyi ADP1 mutants reveals a functional redundancy in the recruitment of multidrug efflux systems. PLoS One 2013;8:e56090.

187. Fujita M, Shiota S, Kuroda T, Hatano T, Yoshida T, Mizushima T, et al. Remarkable synergies between baicalein and tetracycline, and baicalein and ß-lactams against methicillin-resistant Staphylococcus aureus. Microbiol Immunol 2005;49:391-6.

188. Gibbons S, Oluwatuyi M, Veitch NC, Gray Al. Bacterial resistance modifying agents from Lycopus europaeus. Phytochemistry 2003;62:83-7. 